\title{
RECURSOS PARATEXTUALES Y PARALINGÜISTICOS EN LAS FANPAGES DE LOS PERIODICOS ARGENTINOS CLARÍN Y LA NACIÓN. ATRIBUTOS DEL DISCURSO DE LA PRENSA EN LAS REDES
}

\author{
Dra. Natalia Raimondo Anselmino \\ CONICET, Universidad Nacional de Rosario y Universidad Abierta Interamericana, \\ Rosario, Argentina \\ nraimondo@conicet.gov.ar \\ ORCID iD: https://orcid.org/0000-0001-7217-8754 \\ Ing. Ana Laura Cardoso \\ Universidad Tecnológica Nacional, Facultad Regional Rosario, Argentina \\ cardosoalaura@gmail.com \\ Ing. José Rostagno \\ Universidad Tecnológica Nacional, Facultad Regional Rosario, Argentina \\ joserostagno@hotmail.com \\ Lic. (c) Alejandro Matías Sambrana \\ Universidad Nacional de Rosario, Rosario, Argentina \\ alesambrana@gmail.com
}

Recibido el 27 de febrero de 2019

Aceptado el 13 de agosto de 2019

\section{Resumen}

Este artículo expone parte de los hallazgos producidos en el marco de una investigación interdisciplinar sobre las cuentas oficiales que tienen en Facebook los diarios argentinos Clarín y La Nación, @clarincom y @lanacion, en el período 2010-2015. Con el fin de avanzar en el análisis de las características que adquieren los discursos de la prensa al ser publicados en Facebook, así como conocer el tipo de vínculo que estos medios le proponen a sus respectivos usuarios-lectores en las fanpages examinadas, nos detenemos en el empleo de recursos paratextuales y paralingüísticos - como los corchetes, los hashtags y las menciones, por un lado, y los emoticones o emojis, por el otro.

El diseño metodológico adoptado articula el estudio empírico de la puesta en discurso, propio de la sociosemiótica, con métodos y herramientas provenientes del campo de la ingeniería en sistemas de información orientada a la minería de datos.

Dentro de los principales resultados se destaca no sólo lo concerniente a la distribución diferencial de los distintos recursos paratextuales y paranlingüísticos sino, sobre todo, un conjunto de inferencias acerca de las diversas funciones que 
los mismos cumplen en el marco del discurso de los medios estudiados en Facebook.

Palabras clave: prensa, discurso de información, paratextualidad, recursos paralingüísticos, fanpages, investigación interdisciplinar.

\title{
PARATEXTUAL AND PARALINGUISTIC RESOURCES IN THE FANPAGES OF THE ARGENTINE NEWSPAPERS CLARÍN AND LA NACION. ATTRIBUTES OF PRESS DISCOURSE IN SOCIAL NETWORKING SITES
}

\begin{abstract}
This article exposes part of the findings produced in the framework of an interdisciplinary research on the official accounts that the Argentine newspapers Clarín and La Nación have on Facebook, @clarincom and @lanacion, in the 20102015 period. In order to advance in the analysis of the characteristics that the discourses of the press acquire when being published on Facebook, as well as to know the type of bond that these media propose to their respective users-readers in the examined fanpages, we focus in the use of paratextual and paralinguistic resources — such as brackets, hashtags and mentions, on the one hand, and emoticons or emojis, on the other hand.

The adopted methodological design articulates the empirical study of discursive configuration, typical of sociosemiotics, with methods and tools coming from the field of information systems engineering oriented to data mining.

Among the main results stands out not only what concerns to differential distribution of the various paratextual and paranlinguistic resources but, above all, a set of inferences about the diverse functions that they fulfill within the media discourse studied in Facebook.
\end{abstract}

Keywords: press, information discourse, paratextual, paralinguistic resources, fanpages, interdisciplinary research. 
Introducción

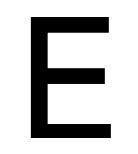

ste artículo procura contribuir al conocimiento que tenemos acerca de los textos periodísticos actuales, específicamente de aquellos que los medios tradicionales de prensa publican a través de sus cuentas en redes sociales en Internet. Para ello, se expone una pequeña parte de los resultados de una investigación interesada por analizar, precisamente, las alteraciones discursivas que son producto de la relación entre los principales periódicos argentinos de información general y alcance nacional —Clarín y La Nación-y la plataforma de Facebook.

El discurso de información —esto es, siguiendo a Verón (2004), ese tipo de discurso que se dirige a un único destinatario genérico, el ciudadano-habitante, y cuyo objeto es una actualidad contada habitualmente desde un registro impersonal- ha sufrido diversas transformaciones a lo largo de su historia. Desde que los diarios tradicionales dejaron de ser exclusivamente impresos y comenzaron a incursionar en el territorio digital online, las propiedades del discurso periodístico fueron adaptándose, de a poco, a ese nuevo ambiente. Incluso, se evidencian ciertas tensiones entre el código escrito y el registro oral, así como entre las normas propias de la comunicación mediática y aquellas más habituales en los intercambios de tipo interpersonal y privado.

Tal como se explica en Raimondo (2012), los cambios socio-tecnológicos que se han dado en el pasaje del texto lingüístico impreso al texto digital y, de ahí, a su puesta online a través de las plataformas conectivas — de acuerdo a la denominación propuesta por Van Dijck (2016) — afectaron las gramáticas de producción, circulación y reconocimiento de los textos. En otras palabras, se trata de una nueva coyuntura que altera las condiciones de producción de los discursos mediáticos contemporáneos y que permite sumar un hito más a la larga serie de modificaciones en las modalidades clásicas de la prensa que vienen siendo analizadas por la semiótica de los medios masivos desde hace ya varios años.

Como lo explican Vázquez-Cano, Fombona y Berna (2016: 589), en este contexto se "altera significativamente la construcción sintáctica, la selección léxica, la ortotipografía y se produce una nueva incorporación de elementos paralingüísticos (icónico-visuales) que enriquecen y modalizan la opinión, la noticia y la argumentación periodística".

En artículos previos —ver Raimondo Anselmino et al. (2017) y Raimondo Anselmino et al. (2018) - se han caracterizado, a grandes rasgos, las peculiaridades que asume el discurso de los periódicos bajo estudio cuando es publicado en Facebook. En este marco, se ha podido analizar la configuración de los posteos que los diarios publicaron en sus respectivas fanpages, @clarincom y 
@lanacion, durante el período 2010-2015. Esto permitió dar cuenta de sus diferentes componentes elementales: texto del post, enlace, imagen y video.

Como texto del post se identifica al enunciado verbal que contiene cada posteonoticia y que se constituye como una unidad informativa. El mismo no sólo comprende texto lingüístico en soporte digital, cuyas frases en algunos casos manifiestan diferentes relaciones de paratextualidad —como, por ejemplo, cuando se emplean corchetes, hashtags y menciones-, sino que a su vez incluye usualmente otros elementos que definimos aquí como paralingüísticos - como los emoticones tipográficos o los emojis. Dichos elementos paratextuales y paralingüísticos no estuvieron siempre presentes a lo largo de todo el período analizado, sino que, como veremos en los siguientes apartados, fueron apareciendo gradualmente.

Recuérdese que fue Genette (1989: 11) quien reconoció la paratextualidad como uno de los cinco tipos de transtextualidad o transcendencia textual que clasificó en su Palimpsestos, y la definió como:

la relación, generalmente menos explícita y más distante, que, en el todo formado por una obra literaria, el texto propiamente dicho mantiene con lo que sólo podemos nombrar como su paratexto: título, subtítulo, intertítulos, prefacios, epílogos, advertencias, prólogos, etc.; notas al margen, a pie de página, finales; epígrafes; ilustraciones; fajas, sobrecubierta, y muchos otros tipos de señales accesorias, autógrafas o alógrafas, que procuran un entorno (variable) al texto.

Se distingue de esta manera un campo de relaciones que, según Genette (1989: 12), "es uno de los lugares privilegiados de la dimensión pragmática de una obra, es decir, de su acción sobre el lector".

Lo paralingüístico, por otra parte, es ubicado por Vázquez-Cano, Fombona y Berna (2016: 520) en un mismo conjunto con lo ortotipográfico, en tanto consideran que en ambos casos se trata de "signos no verbales que acompañan la comunicación lingüística y que complementan la comunicación" y cuya principal función sería "restituir el elemento prosódico y socioemocional del discurso oral" (Vázquez-Cano, Fombona y Berna, 2016: 590).

En el caso de la investigación aquí presentada se reconoce como paralingüístico a esos elementos que forman parte del componente identificado como texto del post, que han sido allí incorporados para acompañar al contenido propiamente lingüístico y muchas veces funcionan como elementos modalizadores del discurso de información. Cabe aclarar, además, que -a diferencia de lo propuesto en Vázquez-Cano, Fombona y Berna (2016) - se excluye de esta categoría a las imágenes, los videos y los hipervínculos mediante URL (Uniform Resource Locator) que reenvían al portal del diario en la web. 
A continuación, se explicitan las principales coordenadas del abordaje teóricometodológico de la investigación objeto de este artículo y se exponen los hallazgos referidos a la utilización de los principales elementos paratextuales y paralingüísticos encontrados: por un lado, los corchetes, los hashtags y las menciones; por otro lado, los emoticones y los emojis. Finalmente, este escrito concluye con algunas inferencias sobre cómo el empleo de los componentes paratextuales y paralingüísticos presentes en los posteos que Clarín y La Nación publican en sus fanpages da cuenta del modo en que, en la actualidad, los diarios enuncian a través de las "redes".

\section{Nota sobre la perspectiva teórico-metodológica adoptada}

Los resultados presentados en este escrito son parte de una investigación mayor, de corte interdisciplinar, que tiene como finalidad analizar cuáles son las características que adquiere el discurso de los diarios Clarín y La Nación cuando es publicado en Facebook y qué tipo de vínculo -en términos de contrato de lectura (Verón, 1985) - le proponen esos medios a sus usuarios-lectores en las fanpages examinadas. Se analizaron, para ello, posteos publicados por @clarincom y @lanacion, durante el período 2010-2015; atendiendo a dos propósitos: por un lado, indagar el tipo de contenido difundido, la frecuencia de publicación, los modos de composición de los posts y las interacciones obtenidas en ambas cuentas $y$, por otro lado, analizar ciertas regularidades en términos de estrategias discursivas teniendo en cuenta factores o rasgos retóricos, temáticos y enunciativos. Es precisamente en relación con este último objetivo, que se han identificado una serie de recursos paratextuales y paralingüísticos que forman parte de las propiedades específicas encontradas en la manera en que los periódicos estudiados enuncian en las redes. El análisis de los mismos no es de tipo lingüístico sino discursivo, en tanto se orienta a caracterizar el empleo de los corchetes, hashtags, menciones, emoticones y emojis para comprender qué lugar desempeñan en la puesta en sentido por parte de la prensa en Facebook.

Se trabajó, concretamente, sobre dos corpus: un corpus de base ${ }^{1}$ y un corpus total. El primero consiste en una colección de 1129 posteos (534 de Clarín y 595 de La Nación) cuyos criterios de conformación han sido precisados en Raimondo, Sambrana y Cardoso (2017) y su recorte temporal se inicia el 25 de octubre de

1 El corpus de base fue conformado atendiendo a criterios de aleatoridad - Raimondo, Sambrana y Cardoso (2017) — y sobre el mismo se relevaron de modo artesanal —es decir, no automatizadamente - seis variables cualitativas ad hoc, categorizadas luego de la observación directa y pormenorizada de cada uno de los posteos y el cotejo de los mismos con las notas publicadas en las versiones online de los diarios a las que dichos posts reenvían, en caso de que hubiera enlace. Como se explica en Raimondo, Sambrana y Cardoso (2017), dichas variables permiten identificar: si el posteo presenta o no texto propio; la localización geográfica de la información publicada; el género periodístico del que se trata; la temática de referencia; la temporalidad de los acontecimientos relatados y; la modalidad discursiva prevalente. 
$2010^{2}$ y concluye el 9 de agosto de 2015. El segundo, por su parte, comprende el universo de todas las publicaciones registradas en ambas fanpages entre el $1^{\circ}$ de enero de 2010 y el 31 de diciembre de 2015 que suman, en total, 54742 posteos (29341 de Clarín y 25401 de La Nación).

Decimos que esta investigación es de carácter interdisciplinar porque, como se explica con mayor detalle en Raimondo, Cardoso y Rostagno (2018), integra el estudio empírico de la puesta en discurso (Verón, 1998) —en tanto perspectiva de análisis orientada a desentrañar el nivel de la enunciación, identificando aquellas operaciones enunciativas regulares, es decir, modalidades del discurso cuyo funcionamiento es relativamente constante- con métodos y herramientas provenientes del campo de la ingeniería en sistemas de información orientados a la minería de datos. Esta amalgama ha hecho menos abrumador el manejo de un paquete de materiales discursivos tan heterogéneo como voluminoso.

\section{El empleo de corchetes y sus diversas funciones}

Los corchetes son, en sentido estricto, un tipo de signo de puntuación. Según Stern (2006: 27), todo signo de puntuación "estructura las diversas unidades del texto y permite organizar la información", al tiempo que se atiene a ciertas normas de uso dentro del sistema de la lengua.

Por su parte, la Real Academia Española (RAE) define al corchete de la siguiente manera: "Signo ortográfico doble ([ ]) usado para incluir información complementaria o aclaratoria en un texto; con tres puntos suspensivos en su interior, para indicar la omisión de parte del texto citado y, en fonética, para encerrar las transcripciones" ${ }^{3}$. Se trata de una definición que nos permite advertir que los corchetes no sólo establecen una determinada función respecto del texto que comprenden en su interior sino, también, que, tal como puede observarse en la imagen 1, junto a dicho contenido —en este caso, el adverbio de tiempo "Ahora" - establecen una determinada relación de paratextualidad (Genette, 1989) con ese otro texto que está por fuera de estos signos pero dentro del texto del post —como "La Presidenta tuiteó..." - o, incluso, con el enunciado que funciona como título del enlace a la nota publicada en el portal del medio - que reza "Traspaso conflictivo...".

2A diferencia de @lanacion — que ya estaba en funcionamiento desde 2009_, es recién en octubre de 2010 cuando la cuenta de Clarín comienza a manifestar una actividad sistemática.

$3 \mathrm{Cfr}$. https://dle.rae.es/?w=corchete 


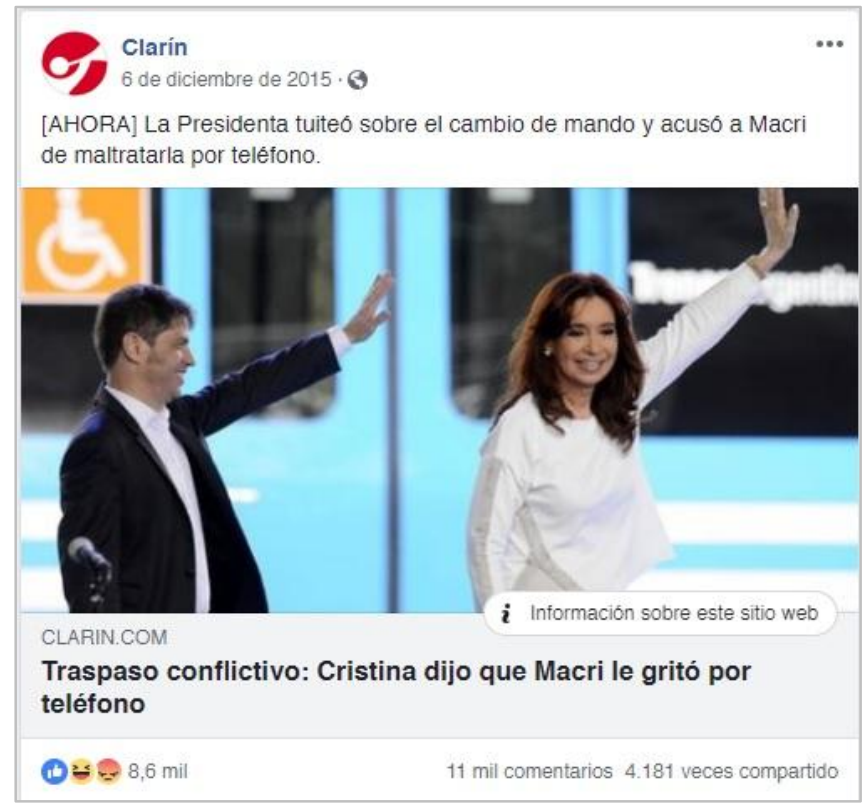

Imagen 1. Posteo de @clarincom con corchetes

Asimismo, vale aclarar que cada publicación en Facebook puede tener más de un par de corchetes (Imagen 2) y estos también se emplean para circunscribir un enlace enterrado — también llamado buried link— en el texto del post ${ }^{4}$ (Imagen 2), destacándolo del resto del contenido verbal. De hecho, al identificar en el corpus total aquellos posteos en los cuales se agregan corchetes al menos una vez (Tabla 1), puede apreciarse que la frecuencia de uso de los mismos como manera de encuadrar un link supera a otras formas de empleo, en el caso de ambas cuentas.

4 Como se explica en Raimondo, Cardoso y Rostagno (2018) al estudiar las publicaciones de las fanpages fue posible reconocer distintos tipos de enlaces a sitio web de acuerdo a cómo estos se visualizan en el posteo: en primer lugar, los links generados al mencionar otras cuentas y lugares de Facebook o emplear algún hashtag, así como cualquier otro enlace que reenvíe a contenidos que se alojan dentro de la plataforma (una encuesta, una promoción, un evento, etc.); en segundo lugar, links generados al compartir una URL de destinación, ya sea completa o acortada, que reenvía a un contenido localizado en Internet y en los cuales la cadena de caracteres de la URL no queda visible porque, en su lugar, se muestran otros elementos ligados al enlace (por ejemplo, un título, una descripción, una imagen, video, etc.) y; en tercer lugar, links generados al ingresar dentro del "texto del post" uno o varios enlace/s enterrado/s, mediante URL completa o acortada, y cuyos caracteres sí pueden verse. 


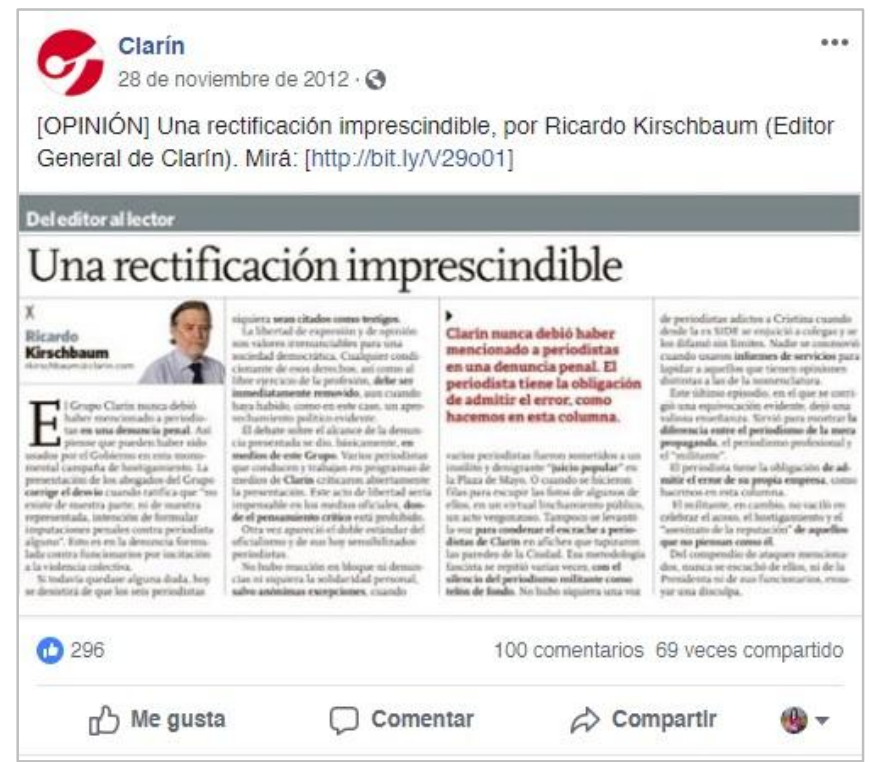

Imagen 2. Posteo de @clarincom con corchetes

La tabla 1 permite hacer otras observaciones; entre ellas que, tanto en Clarín como en La Nación, los corchetes no tienen una presencia demasiado significativa en términos de cantidad sobre el total de publicaciones, aunque en la fanpage del primer periódico se emplea este recurso paratextual con mayor frecuencia que su competidor (Clarín se sirve de él un 64,63\% más que La Nación). Ahora bien, si revisamos la distribución de los posteos con al menos un corchete a lo largo del tiempo, veremos que estos recursos aparecen recién en el año 2011, presentan una considerable variación durante el período estudiado y su distribución es muy diferente entre las cuentas analizadas (gráficos 1 y 2). Durante 2011 ambos medios ya exhiben un porcentaje de uso similar inferior al 15\%. Entre 2012 y 2013, @clarincom hace un uso intensivo de este recurso —alcanzando el 71,01\% y el $60,79 \%$ de los posteos totales de los años mencionados- mientras que en el mismo periodo @lanacion duplica su empleo con respecto al año 2011 pero solo alcanza el $24,25 \%$ y el $17,03 \%$, respectivamente. 
Tabla 1. Posteos con al menos un par de corchetes en corpus total por diario

\begin{tabular}{|l|r|r|r|r|}
\hline \multirow{2}{*}{} & \multicolumn{2}{|c|}{ Clarín } & \multicolumn{2}{c|}{ La Nación } \\
\cline { 2 - 5 } & \multicolumn{1}{|c|}{$\begin{array}{c}\text { Posteos con } \\
\text { corchetes }\end{array}$} & $\begin{array}{c}\text { \% sobre el } \\
\text { total de } \\
\text { posteos }\end{array}$ & $\begin{array}{c}\text { Posteos con } \\
\text { corchetes }\end{array}$ & $\begin{array}{c}\text { \% sobre el } \\
\text { total de } \\
\text { posteos }\end{array}$ \\
\hline Encuadran links & 4014 & $13,68 \%$ & 2053 & $8,08 \%$ \\
\hline Circunscriben & 1826 & $6,22 \%$ & 1233 & $4,85 \%$ \\
\hline frases & 416 & $1,42 \%$ & 3 & $0,01 \%$ \\
\hline Ambos usos & 6256 & $21,32 \%$ & 3289 & $12,95 \%$ \\
\hline
\end{tabular}

Fuente: elaboración propia.

Cabe destacar que, al analizar más detalladamente los porcentajes arrojados entre 2010 y 2013, se advierte que @clarincom utiliza los corchetes principalmente para enmarcar enlaces (Gráfico 1), mientras que este tipo de uso de los corchetes es recién empleado por @lanacion en el año 2015 (Gráfico 2) ${ }^{5}$. Por su parte, los corchetes que circunscriben frases crecen notoriamente en ambas cuentas durante 2012, año en que, aproximadamente, uno de cada cuatro posteos manifiesta al menos una vez este atributo paratextual.

Luego, en el año 2014, se nota que la proporción de uso en ambas cuentas sufre una marcada disminución hasta llegar a valores cercanos al 10\%; esto quiere decir que @clarincom pasó de utilizar corchetes en tres de cada cinco posteos en 2013 a hacerlo en solo uno de cada diez el año siguiente. Tal situación puede deberse a que fue precisamente en 2014 -Cfr. El-Arini (2014)— cuando Facebook comienza a promover la visualización jerarquizada de los posteos que comparten enlaces vía cardlink en detrimento de los links "enterrados".

En el año 2015 @clarincom continúa con la tendencia decreciente con el 5,96\%, mientras que @lanacion aumenta al 13,57\% debido a la incorporación del uso de los corchetes para enmarcar links.

5 En los años anteriores a 2015 se observa que @lanacion emplea otra estrategia para destacar los enlaces enterrados en el texto del post: en vez de encerrarlos entre corchetes los coloca luego de sintagmas como "Más info:" o "Nota:". 
- Natalia Raimondo Anselmino, Ana Laura Cardoso, José Rostagno, Alejandro Matías Sambrana

Fuente: elaboración propia

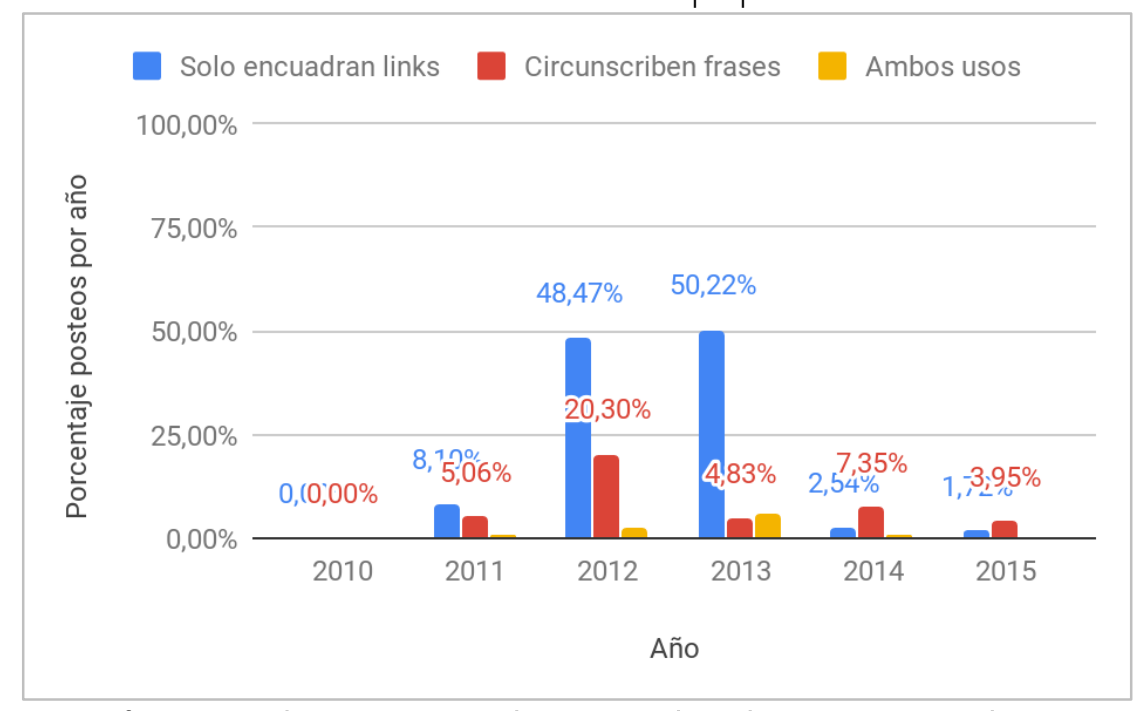

Gráfico 1. Distribución por año de posteos de @clarincom con corchetes en corpus total

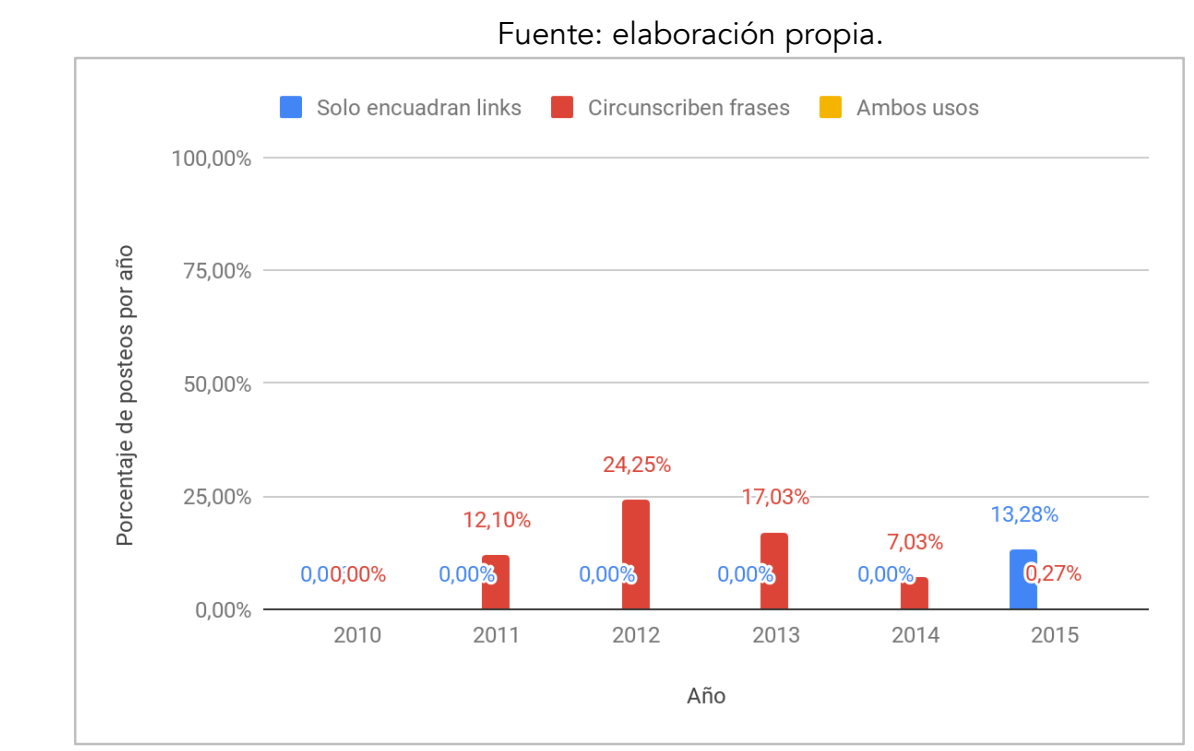

Gráfico 2. Distribución por año de posteos de @lanacion con corchetes en corpus total

Si pasamos de considerar el corpus total para detenemos en el corpus de base y nos limitamos, específicamente, a los corchetes que circunscriben frases-donde, vale aclarar, sólo el 10,54\% $(n=119)$ de los 1129 posteos presentan este tipo de recurso (Tabla 2) - , podemos trazar varias diferencias en el comportamiento de ambas fanpages. 
Tabla 2. Posteos con corchetes que circunscriben frases en corpus de base según temporalidad de los acontecimientos

\begin{tabular}{|c|r|r|r|r|}
\hline \multirow{2}{*}{} & \multicolumn{2}{|c|}{ Clarín } & \multicolumn{2}{|c|}{ La Nación } \\
\cline { 2 - 6 } & $\begin{array}{r}\text { Cant. de } \\
\text { posteos }\end{array}$ & $\begin{array}{l}\text { \% sobre el total } \\
\text { con corchetes }\end{array}$ & $\begin{array}{c}\text { Cant. de } \\
\text { posteos }\end{array}$ & $\begin{array}{c}\text { \% sobre el total con } \\
\text { corchetes }\end{array}$ \\
\hline No corresponde & 0 & $0,00 \%$ & 0 & $0,00 \%$ \\
\hline Pasado & 17 & $21,25 \%$ & 13 & $33,33 \%$ \\
\hline Presente & 45 & $56,25 \%$ & 10 & $25,64 \%$ \\
\hline Instante & 9 & $11,25 \%$ & 7 & $17,95 \%$ \\
\hline Futuro & 9 & $11,25 \%$ & 9 & $23,08 \%$ \\
\hline Totales & 80 & $100,00 \%$ & 39 & $100,00 \%$ \\
\hline
\end{tabular}

Fuente: elaboración propia.

Como es posible distinguir en el gráfico 3, los corchetes que se emplean para circunscribir frases son un recurso con mayor preponderancia en dos géneros periodísticos en particular: en el caso de La Nación, un 69,23\% ( $n=27)$ se concentra en las Noticias y, en segundo lugar aunque muy por detrás $(10,26 \%)$, en los Anuncios o posteos de saludo a usuarios ${ }^{6}$; mientras que en Clarín alrededor del $63,75 \%$ se concentra en los Anuncios o saludos a usuarios y un $23,75 \%$ en las Noticias.

6 En Raimondo Anselmino et al. (2017: 67) definimos al Anuncio o posteo de saludo a usuarios como un nuevo tipo de género, propio de la plataforma de Facebook, que "a diferencia de los géneros que tradicionalmente han sido considerados como periodísticos (de Fontcuberta, 2001), no necesariamente refiere a algún tipo de acontecimiento noticiable ni tampoco a ideas expresadas o defendidas argumentativamente". Retomando la clásica distinción realizada por Bajtín (1998), puede decirse que el mismo consiste en un híbrido entre géneros discursivos primario y secundario y brinda soporte a un procedimiento de identificación que forma parte de lo que, siguiendo a Biselli y Valdettaro (2004), podemos llamar estrategias discursivas del contacto. 
Fuente: elaboración propia.

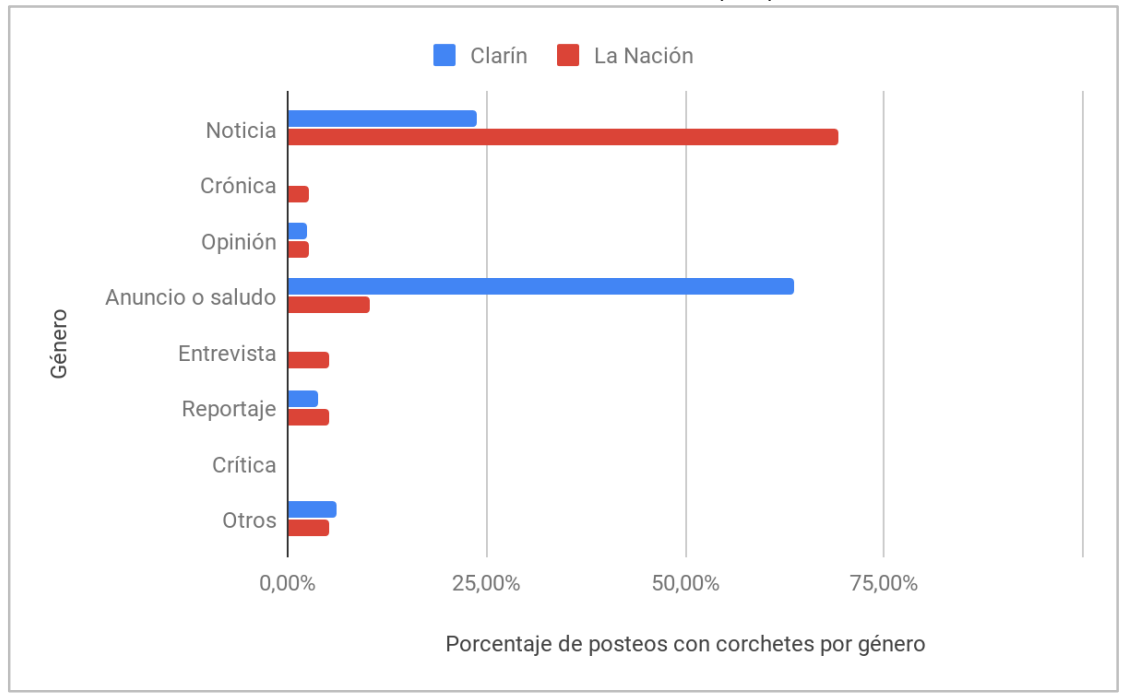

Gráfico 3. Posteos con corchetes según género periodístico en corpus de base

Otra diferencia entre ambas cuentas se deriva del cruce entre la presencia de corchetes que circunscriben frases y la variable temática de referencia: mientras que en@clarincom se concentran preferentemente en publicaciones ligadas con el entretenimiento $(53,75 \%)$ y, en menor medida, sobre política $(17,50 \%)$ y deportes $(11,25 \%)$; en @lanacion, el ranking es encabezado por política $(38,46 \%)$ y sociedad $(23,08)$.

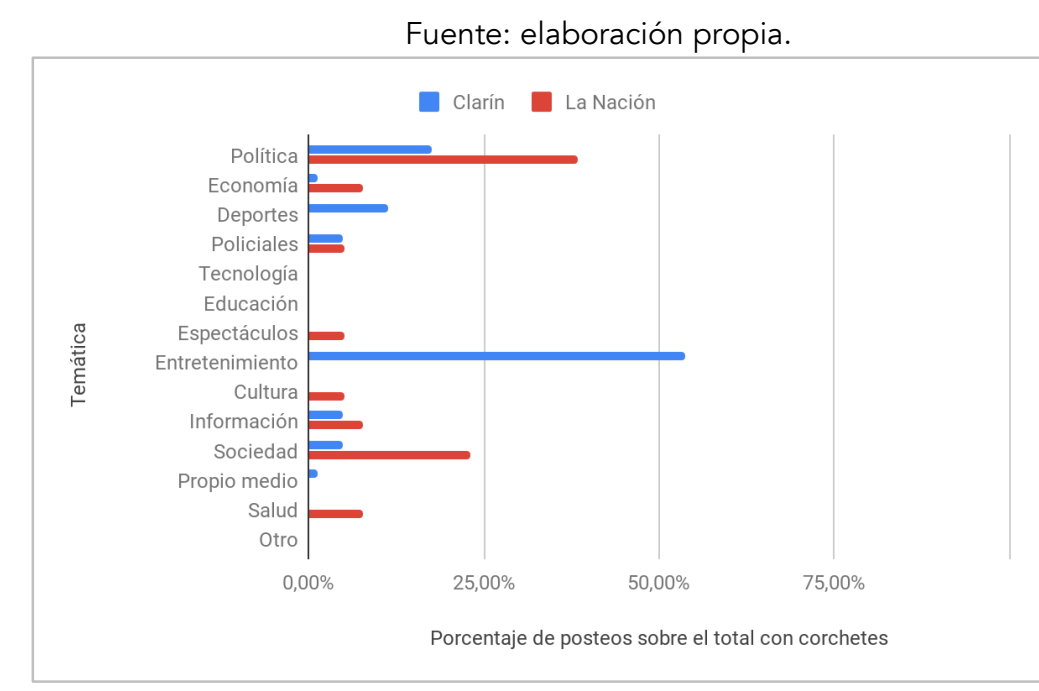

Gráfico 4. Posteos con corchetes según temática de referencia en corpus de base

Del mismo modo, si observamos el uso de corchetes respecto de la variable temporalidad de los acontecimientos presentados — que registra si se refieren al pasado, al presente, al instante o al futuro-, vemos que en @clarincom se destaca su uso en el presente (casi el 60\% de los casos). @lanacion, en cambio, 
tiene una distribución más equitativa, donde el pasado se encuentra en primer lugar con casi el 33\% de los casos (Tabla 2).

Por otro lado, si contemplamos la distribución de estos corchetes según el momento del día ${ }^{7}$ en que se publicaron los posteos (Tabla 3), en Clarín es la noche la franja horaria en la que se emplean con mayor frecuencia los corchetes. Esto se condice, precisamente, con la frase entre corchetes más utilizada según la imagen 3 y con el momento del día en donde crecen las publicaciones que ubicamos dentro del género Anuncio o posteo de saludo a usuarios, que representan el $36 \%$ de todos los posteos nocturnos de la cuenta. La Nación, en cambio, hace lo suyo durante la tarde. Como ya se ha señalado en Raimondo Anselmino et al. (2017), las estrategias ligadas a los momentos de publicación no han sido siempre las mismas entre ambas cuentas.

Tabla 3. Distribución de posteos con corchetes que circunscriben frases en corpus total según franja horaria

\begin{tabular}{|l|r|r|r|r|}
\hline \multirow{2}{*}{} & \multicolumn{2}{|c|}{ Clarín } & \multicolumn{2}{c|}{ La Nación } \\
\cline { 2 - 5 } & $\begin{array}{c}\text { Cant. de } \\
\text { posteos }\end{array}$ & $\begin{array}{c}\text { \% sobre el total con } \\
\text { corchetes }\end{array}$ & $\begin{array}{c}\text { Cant. de } \\
\text { posteos }\end{array}$ & $\begin{array}{c}\text { \% sobre el total } \\
\text { con corchetes }\end{array}$ \\
\hline Mañana & 389 & $17,35 \%$ & 450 & $36,41 \%$ \\
\hline Tarde & 534 & $23,82 \%$ & 645 & $52,18 \%$ \\
\hline Noche & 1156 & $51,56 \%$ & 135 & $10,92 \%$ \\
\hline Madrugada & 163 & $7,27 \%$ & 6 & $0,49 \%$ \\
\hline Total & 2242 & $100 \%$ & 1236 & $100 \%$ \\
\hline
\end{tabular}

Fuente: elaboración propia.

7 La madrugada comprende entre la 1 y las 6:59 AM; la mañana, entre las 7 AM y las 12:59 PM; la tarde, desde la 1 hasta las 6:59 PM y; la noche, entre las 7 PM y las 00:59 AM. 
Fuente: elaboración propia.

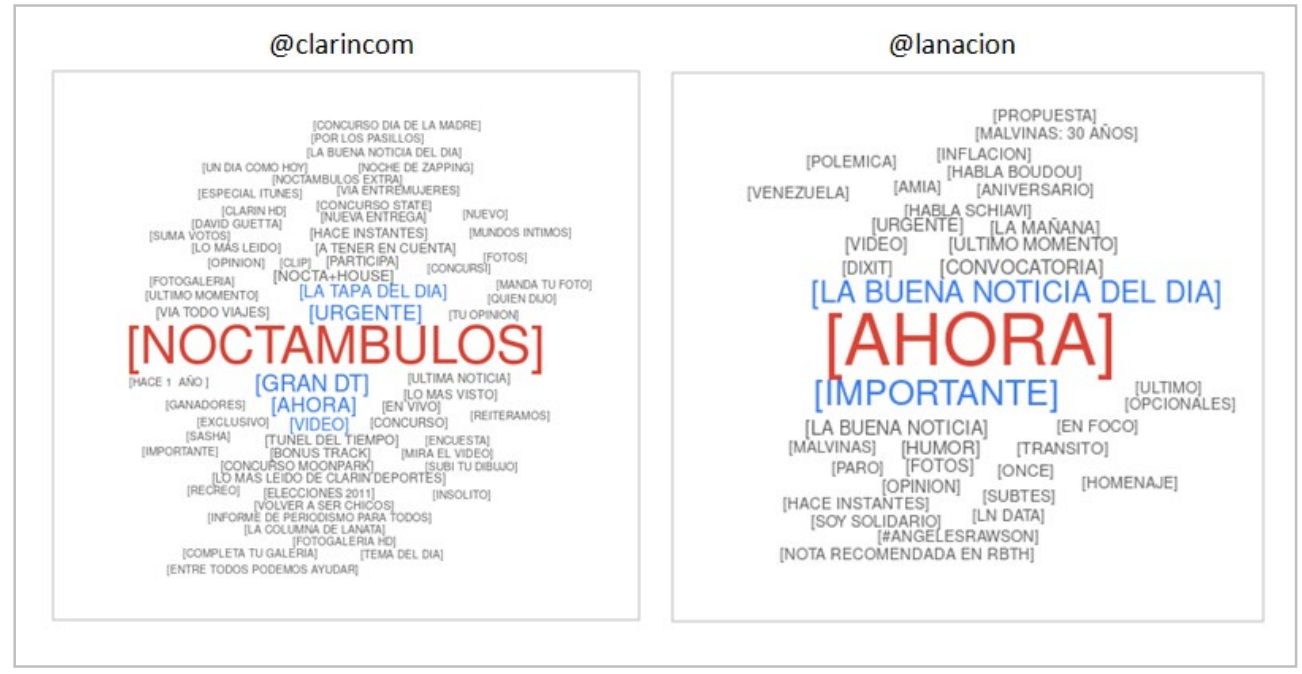

Imagen 3. Nubes de palabras con frases circunscritas por corchetes en corpus total

Finalmente, algunas precisiones más sobre el comportamiento discursivo de este tipo de recurso paratextual en las cuentas analizadas.

Como se ha dicho, los corchetes se han utilizado para encuadrar enlaces $-\mathrm{y}$, así, distinguir un link enterrado en el texto del post que redirecciona el tráfico de usuarios al contenido publicado por el medio en su sitio web- o bien para circunscribir frases. Puede agregarse, además, que cuando los corchetes comprenden enlaces todo el conjunto es presentado al final del texto del post, mientras que en los otros casos se lo encuentra, la mayoría de las veces, al comienzo (ver imagen 2). Por lo general, estas frases tienen las siguientes características ${ }^{8}$ :

- son muy breves e, incluso, pueden estar compuestas por una sola palabra;

- se encuentran dispuestas totalmente en mayúscula, en vez de mayúscula/minúscula, y;

- cuando presentan una modalidad declarativa suelen cumplir una función cercana a la atribuida a la volanta o al cintillo", aunque su contenido no necesariamente se condice con lo expresado en alguno de los elementos del titulado que el diario dispone en la noticia misma (publicada ya sea en su ejemplar impreso o en su edición online) y representan, por ello, una

8 Es @lanacion la cuenta que presenta más excepciones en todos los aspectos mencionados en el párrafo.

9 Según el Manual de Estilo de Clarín (1997: 37), la volanta "ubica y anticipa sobre lo que informa el título, es una definición temática y puede agregar información" (p. 37). El cintillo, por su parte, es un enunciado breve que anticipa pero, también, "unifica un tema cuando su desarrollo exige más de una página". 
propiedad específicamente elaborada para el discurso del medio en su fanpage.

Más precisamente, la exploración sistemática de los posteos ha permitido reconocer que las frases circunscritas entre corchetes pueden desempeñar una o varias de las siguientes funciones:

- incluir el acontecimiento versado dentro de la diagramación taxonómica del medio, es decir, ubicarlo en algunas de las secciones temáticas que forman parte de "los sistemas de clasificación utilizados por cada diario como un tablero semántico" (Verón, 1983: 94). Por ejemplo: [POLíTICA]; [NOCTÁMBULOS]; [LN DATA]; [GRAN DT] ${ }^{10}$;

- identificar un tema. Por ejemplo: [COPA DAVIS]; [BOCA CAMPEÓN]; [VIOLENCIA EN EL FÚTBOL];

- ubicar temporalmente la información brindada, generalmente para resaltar su novedad y captar la atención del público, a través de adverbios deícticos o locuciones adverbiales que, sobre todo, especifican simultaneidad o una muy reciente anterioridad. Por ejemplo: [AHORA]; [ÚLTIMO MOMENTO]; [HACE INSTANTES]; [URGENTE].

- localizar geográficamente la información. Por ejemplo: [Córdoba]; [Calafate]; [Chile]; [VENEZUELA].

- interpelar directamente al lector-usuario, en algunos casos empleando el modo gramatical imperativo, en otros adoptando una lógica modal deóntica y dando lugar a esa modalidad intersujeto que Culioli (en Fisher y Verón, 1986) caracterizó como Modalidades-411. Por ejemplo: [ATENCIÓN]; [PARTICIPA]; [A TENER EN CUENTA]; [IMPORTANTE].

10 Vale señalar que, en ambas cuentas, la sección más nombrada dentro de corchetes es aquella que cada uno de los medios construyó específicamente en la plataforma de Facebook, tal como puede visualizarse en las nubes de palabras de la imagen 3. En el caso de Clarín, se destaca "NOCTÁMBULOS", vocativo (expresado solo o en compañía de corchetes o hashtags) que sirve tanto para interpelar a parte del colectivo de lectores-usuarios como, también, para denominar a una especie estable de posteos publicados en las franjas horarias de la noche o la madrugada —un total de 946 posteos comprendidos en el corpus total- entre los años 2011 y 2014 . En La Nación, "LA BUENA NOTICIA DEL DÍA" serializa un conjunto de posteos del corpus total cuya primera publicación tiene lugar en 2011; no siempre se escribe entre corchetes y puede tener alguna pequeña variación (por ejemplo, "la buena noticia", "la buena noticia de hoy" o "la buena noticia del lunes", etc.), pero su empleo entre corchetes concentra su distribución, precisamente, durante los dos últimos meses de ese año y en 2012, para luego emplearse en ocasiones muy aisladas. Tras dicho sintagma, que opera a modo de cintillo, la cuenta solía publicar alguna noticia "optimista".

11 Se trata de enunciados que proponen "una relación modal que pone en juego Ego y Alter, el enunciador y el co-enunciador" (Fisher y Verón, 1986), cuyo ejemplo más expresivo es, precisamente, el de la interpelación. Como ya lo han explicado Fisher y Verón (1986), los enunciados en los que está presente este tipo de modalidad son aquellos que se dirigen a un co-enunciador anónimo que se propone como co-presente, co-temporáneo de la enunciación (es decir, como no habiendo desface temporal) y pueden caracterizarse por la presencia de frases interrogativas u otras marcas como la segunda persona (del singular o el plural) o el modo del verbo. 
- distinguir el tipo de contenido mediático que se comparte a través del posteo. Por ejemplo: [VIDEO]; [EN VIVO]; [CONCURSO]; [FOTOGALERÍA];

- calificar el acontecimiento a través de sustantivos axiológicos y adjetivos afectivos 0 evaluativos que expresan un juicio de apreciación/depreciación o manifiestan una reacción emocional. Por ejemplo: [IMPACTANTE TESTIMONIO]; [INSÓLITO]; [HORROR]; [TRISTE NOTICIA].

Como puede verse, si bien en algunos casos la frase entre corchetes tiene una clara función referencial (Jakobson, 1975), en muchas otras ocasiones vehiculizan rasgos expresivos o conativos del discurso de información -y hasta, puede advertirse, tienen a veces una función fática- que no se encontraban presentes en las notas que los medios publican en su ejemplar impreso y/o en su edición online ${ }^{12} \mathrm{y}$, por lo tanto, constituyen una propiedad peculiar del modo en que Clarín y La Nación enuncian en Facebook.

\section{Los hashtags y menciones como elementos transtextuales}

Entre los elementos paratextuales que son objeto de análisis en este artículo se encuentran, también, el hashtag y la mención. Ambos cuentan con una característica distintiva: funcionan como hipervínculos —en el sentido técnico, y no genetteano, del término- que linkean fragmentos del texto del post con otros contenidos alojados en la misma plataforma de Facebook. Así también, tienen algunas de las cualidades típicas de los hipervínculos online.

Cassany (2003: 5) distingue a estos recursos por su condición de enlaces electrónicos, según la cual reúnen las características de hiper e intertextualidad. Por un lado, en tanto hipertextos, los posteos que incluyen hashtags o menciones poseen una "organización en forma de conjunto interconectado de fragmentos [que] favorece la existencia de diferentes itinerarios de lectura, que avanzan saltando de una unidad a otra a través de los vínculos"; por otro lado, su intertextualidad supone que estos elementos generan relaciones con otros discursos, distintos al texto del post en el que se encuentran, aunque todos alojados en la misma plataforma. El autor enumera también algunas ventajas de este tipo de vínculos:

\footnotetext{
12 Este párrafo evoca la clásica tipología de funciones del lenguaje según Jakobson (1975: 353) en la que, a grandes rasgos, se distingue entre: 1) la función referencial, que es aquella orientada hacia el referente o contexto; 2) la función emotiva (o expresiva), que "apunta a una expresión directa de la actitud del hablante ante aquello de lo que está hablando" (p. 353); 3) la función conativa, orientada hacia el destinatario del mensaje; 4) la función fática, que procura "establecer, prolongar o interrumpir la comunicación (...) para llamar la atención del interlocutor o confirmar si su atención se mantiene" (p. 356); 5) la función metalingüística, que tiene lugar "cuando el destinador y/o destinatario quieren confirmar que están usando el mismo código" y; 6) la función poética, que está orientada hacia el mensaje mismo.
} 
- "Son pro-activos ya que se refieren a sitios del presente, o del futuro, puesto que los documentos se van actualizando" (p.5) y, en este sentido, pueden remitir a actualizaciones en tiempo real de las publicaciones en el muro de un perfil mencionado o de los posteos que incluyan determinado hashtag;

- "Son accesibles de modo inmediato y eficaz" (p.5) y, por lo tanto, no requieren una nueva acción de búsqueda para ampliar la lectura, sino que basta un clic;

- Se centran en "el contenido del documento citado y en su interés para el posible lector" (p.5), y no simplemente en citar su autoría, como en las referencias bibliográficas del texto analógico.

A su vez, Cassany (2003: 6), parafraseando a Burbules (1998), critica "la noción ingenua de enlace como conexión simple o neutra" y afirma: "se trata de un mecanismo activo que contribuye a crear significado. [...] Los enlaces a través de los que se llega a un determinado texto influyen en la construcción de su significado".

En sentido estricto, un hashtag o etiqueta es una secuencia de caracteres alfanuméricos no mediados por espacios, antecedidos por el símbolo de almohadilla o numeral (\#), que puede contener palabras, frases o siglas. Se trata de etiquetas que "se utilizan para facilitar el seguimiento de un tema 'etiquetándolo' con esa cadena de caracteres" (Tascón, 2012: 38).

Si bien el uso de la combinación numeral+caracteres tiene sus antecedentes en el desarrollo de las telecomunicaciones y el lenguaje de programación, el hashtag, tal como lo conocemos hoy, nació en Twitter como una forma de organizar el universo de tuits contenidos en la plataforma e identificar puntas de ovillo desde las cuales recuperar publicaciones que tuvieran una etiqueta común ${ }^{13}$. Desde entonces, otras redes sociales en Internet fueron incorporando esta función: Instagram y Google+ en 2011, Pinterest en 2012, Vine y Flickr en 2013. Facebook se sumó a esta lista también en 2013 , en parte como consecuencia de la adquisición que hiciera de Instagram, plataforma que ya utilizaba el hashtag.

13 Tal como recuerda González-Fernández-Villavicencio (2014), su primera utilización en la plataforma de Twitter fue realizada en agosto de 2007, cuando Chris Messina propuso la etiqueta \#barcamp para agrupar a todas las publicaciones sobre una serie de conferencias. En principio, Twitter se resistió a incluir este proceso de etiquetamiento entre las prestaciones de su plataforma. Aún así, en octubre del mismo año, la etiqueta \#sandiegofire, utilizada por los periodistas por sugerencia de Messina para informar acerca de incendios forestales en San Diego, se convirtió en una herramienta de valiosa utilidad para los usuarios de la red social. Recién en 2009 Twitter hizo oficial su uso, siendo la primera plataforma conectiva en convertir en hipervínculos toda "palabra o frase sin espacios, precedida del símbolo de la almohadilla" (González-Fernández-Villavicencio, 2014: 326) o numeral (\#). 
En cuanto a su función actual, puede afirmarse que el hashtag nació como una manera de condensar significaciones en una reducida extensión de caracteres. Puntualmente, Menna (2012: 4) dirá que "este signo '\#' más la secuencia de caracteres que le sigue, indica 'tema abierto' al que cualquier usuario puede referir o realizar una aportación incluyendo la etiqueta". Así también, la autora considera que estas etiquetas presentan una codificación que "las convierte en híbridos entre palabras, frases, eslóganes...una suerte de minidiscursos, micromanifiestos, mínima declaración de intenciones" (2012: 6), y contienen características menos lingüísticas y más semióticas, lo cual les permite una estructura flexible.

Esta compleja codificación da como resultado, según Yus (en Menna, 2012: 33), un esquema comprimido que, para su decodificación, "requiere un esfuerzo extra". Asimismo, desde dicha mirada pragmática sobre este asunto, a la hora de decodificar un hashtag cobra especial importancia la polifonía textual que va adherida a ellos: "La posibilidad del discurso de incluir un coro de voces que sostienen o refutan lo que decimos, se convierte en una estrategia pragmática al servicio de la argumentación y de la relevancia" (Menna, 2012: 34).

De esta manera, puede verse que la etiqueta abandona su tradicional función clasificatoria e interviene en los nuevos modos de titular que presenta el discurso de información contemporáneo (Menna, 2012: 38). Desde el punto de vista del encuadre del discurso (Verón, 2004), puede pensarse que los hashtags, operando paratextualmente, se asemejan a los titulares en tanto condensan las dos dimensiones fundamentales que Verón (2004) atribuye a los mismos: la metalingüística y la referencial ${ }^{14}$.

Sobre el análisis de los posteos recopilados en el corpus total, puede afirmarse que el hashtag es un recurso paratextual menos utilizado que el de los corchetes -el porcentaje de publicaciones con \# respecto del total de posts de cada fanpage es considerablemente bajo-, al tiempo que puede verse que @lanacion los emplea con mayor asiduidad que @clarincom (Tabla 4$)^{15}$.

\footnotetext{
14 Dice Verón (2004: 82) que todo título tiene una dimensión metalingüística, es decir, "se trata siempre del título de un discurso que se presenta después de él; en este sentido un título califica a este último, lo nombra. Además, todo título tiene una dimensión referencial: como el discurso del cual es el nombre, habla también de "algo»" [la cursiva es del autor].

15 Con la singularidad de que la fanpage de La Nación publicó entre 2010 y 2015 un total de 287 hashtags distintos, que en muchos casos reutiliza en varios posteos, mientras que Clarín presenta 406 hashtags diferentes (es decir, los replica menos).
} 
Tabla 4. Uso del hashtag por cuenta en ambos corpus

\begin{tabular}{|l|r|r|r|r|r|r|}
\hline & \multicolumn{3}{|c|}{ Clarín } & \multicolumn{3}{c|}{ La Nación } \\
\cline { 2 - 7 } & $\begin{array}{c}\text { Posteos } \\
\text { con } \\
\text { hashtag }\end{array}$ & $\begin{array}{l}\text { Posteos } \\
\text { Totales }\end{array}$ & $\begin{array}{c}\text { \% sobre el } \\
\text { total de } \\
\text { posteos }\end{array}$ & $\begin{array}{c}\text { Posteos } \\
\text { con } \\
\text { Hashtag }\end{array}$ & $\begin{array}{l}\text { Posteos } \\
\text { Totales }\end{array}$ & $\begin{array}{c}\text { \% sobre el } \\
\text { total de } \\
\text { posteos }\end{array}$ \\
\hline $\begin{array}{l}\text { Corpus de } \\
\text { base }\end{array}$ & 30 & 534 & $5,62 \%$ & 65 & 595 & $10,92 \%$ \\
\hline Corpus total & 1.461 & 29.341 & $4,98 \%$ & 2.248 & 25.401 & $8,85 \%$ \\
\hline
\end{tabular}

Fuente: elaboración propia.

Resulta interesante ver, no obstante, la evolución de este comportamiento a lo largo de los años estudiados (Gráfico 5). Si bien ambos medios comparten un importante crecimiento en 2013 —dado que es en junio de ese año que Facebook habilitó la función de hipervincular los hashtags y empezaron a ser mostrados como hipervínculos (Imagen 4)—, esta tendencia fue mucho más notoria en la cuenta de Clarín, que cerró dicho año con casi un cuarto $(24,66 \%)$ de sus posteos con hashtags (es decir, 874 sobre 3435). Por su parte, @lanacion concentra sus posteos con etiquetas en el año 2015, momento en el que emplea esta herramienta en el $13 \%$ de sus publicaciones. Por el contrario, luego de su pico en 2013 Clarín mantuvo un rápido y sostenido decrecimiento hacia el final del período analizado.

Gráfico 5 - Distribución por año de posteos con hashtags en corpus total

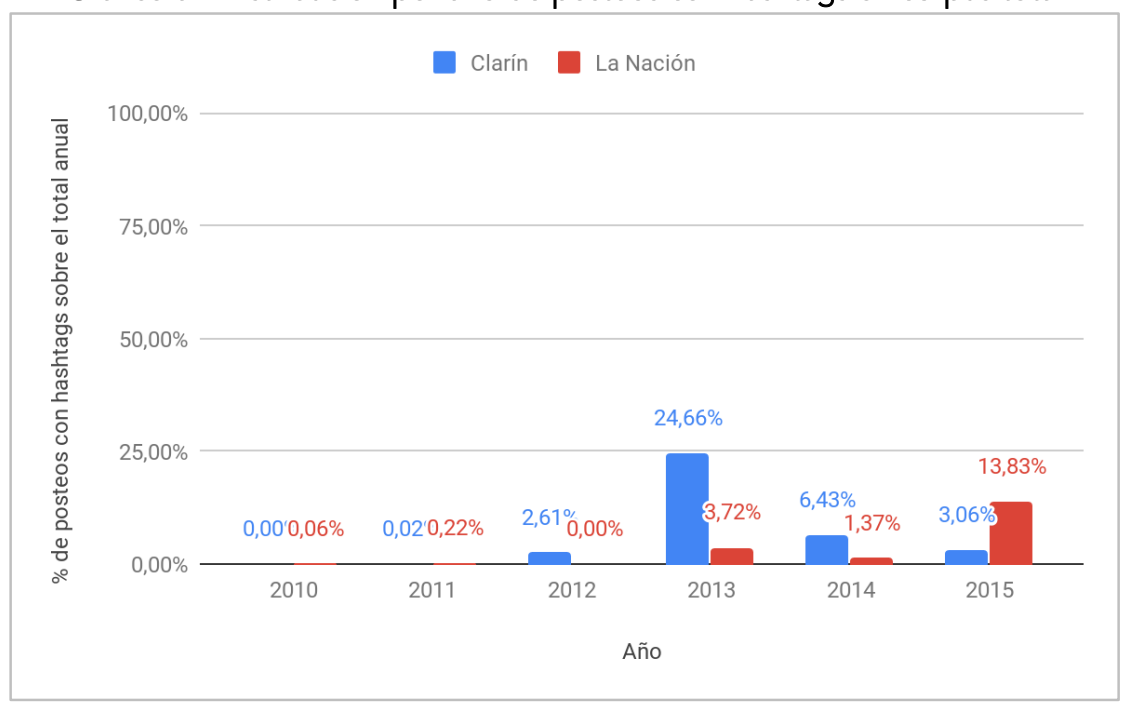

Fuente: elaboración propia. 


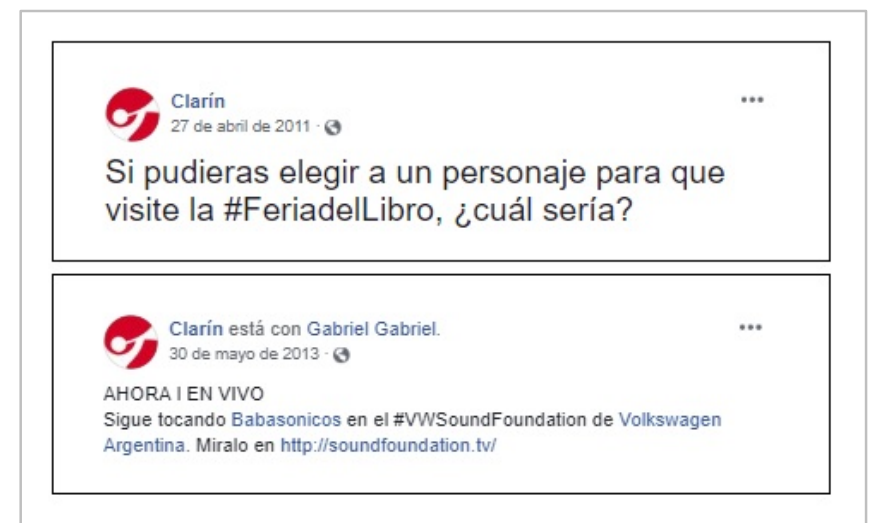

Imagen 4. Comparación de posteos de @clarincom pre y post junio de 2013

Al analizar los posteos con etiquetas por turno de publicación (Tabla 5), puede verse que casi la mitad de los pertenecientes a @clarincom se publicaron por la noche y el resto se reparte equitativamente entre la mañana y la tarde, quedando relegada, en último lugar, la madrugada. Sin embargo, durante 2013, año de mayor utilización de hashtags por parte de esta cuenta, se destaca su empleo en la última franja horaria, alcanzando el $40,43 \%(n=95)$ del total de las publicaciones con etiqueta. En proporción, la madrugada es, también, la segunda franja horaria que más utiliza este recurso paratextual en la fanpage de Clarín, superando ampliamente los valores de la mañana y la tarde. Por su parte, @lanacion emplea este tipo de posteos mayormente por la mañana; un escalón más abajo se encuentran la tarde y la noche. En esta fanpage la utilización del hashtag durante la madrugada aparece recién en 2015, año en el cual el 13,04\% de los posteos que contienen etiquetas son publicados en ese turno ${ }^{16}$. Cabe destacar también que, a lo largo de todo el período estudiado, el 12,43\% de los posteos subidos durante la madrugada por La Nación contienen hashtags. Esta información sobre la distribución del recurso paratextual según el momento del día permite entrever el modo en que los periódicos adaptan gradualmente sus rutinas productivas a las nuevas lógicas del consumo de información en Internet.

16 En Raimondo, Sambrana y Cardoso (2017) se advierte, siguiendo a Levenberg (2017), que en 2015 @lanacion presenta un incremento de sus publicaciones durante la madrugada debido a los cambios en las rutinas productivas del medio. 
Tabla 5. Distribución de posteos con hashtag según franja horaria en corpus total

\begin{tabular}{|l|r|r|r|r|}
\hline \multirow{2}{*}{} & \multicolumn{2}{|c|}{ Clarín } & \multicolumn{2}{c|}{ La Nación } \\
\cline { 2 - 5 } & $\begin{array}{c}\text { Cant. de posteos } \\
\text { con hashtag por } \\
\text { turno }\end{array}$ & $\begin{array}{c}\text { Cant. de } \\
\text { con hashtags } \\
\text { posteos con } \\
\text { hashtag por } \\
\text { turno }\end{array}$ & $\begin{array}{c}\text { \% sobre el total } \\
\text { con hashtags }\end{array}$ \\
\hline Mañana & 328 & $22,45 \%$ & 1152 & $51,25 \%$ \\
\hline Tarde & 343 & $23,48 \%$ & 580 & $25,80 \%$ \\
\hline Noche & 647 & $44,28 \%$ & 369 & $16,41 \%$ \\
\hline Madrugada & 143 & $9,79 \%$ & 147 & $6,54 \%$ \\
\hline Totales & 1461 & $100 \%$ & 2248 & $100,00 \%$ \\
\hline
\end{tabular}

Fuente: elaboración propia.

Al enfocarnos en los datos obtenidos del corpus de base - donde 30 posteos de @clarincom y 65 de @lanacion presentan etiquetas, sobre un total de 534 y 595 publicaciones, respectivamente-, pueden observarse algunas aplicaciones del hashtag similares y otras diferentes en cada fanpage. En primer lugar, ambos medios comparten su empleo en posteos de los géneros periodísticos Otros -es decir, de aquellos posteos que no pudieron ser identificados dentro de ningún género-y Anuncio o posteo de saludo a usuarios que, juntos, concentran el $63 \%$ de las publicaciones con etiquetas en Clarín y el 74\% en La Nación (Gráfico 6). Vale mencionar que, como se dijo en Raimondo, Sambrana y Cardoso (2017: 49), se trata de dos categorías que revisten "una peculiaridad propia del tipo de mensajes que circulan en esta RSI [y dan cuenta de] ciertas operaciones por medio de las cuales las cuentas oficiales de los diarios estudiados procuran adaptarse y ajustarse a las rutinas domésticas y cotidianas de su potencial audiencia".

Por otro lado, Clarín dedica un tercio de sus publicaciones con hashtags (33,33\%) a posteos del género Noticia, mientras que en el mismo rubro La Nación apenas lo hace en un $6,15 \%$. Se destaca también la utilización que hace el último medio de esta herramienta en posts de Opinión (que arriba al 10,77\%), mientras que su competidor no registró ningún hashtag en esta categoría. 
Fuente: elaboración propia.

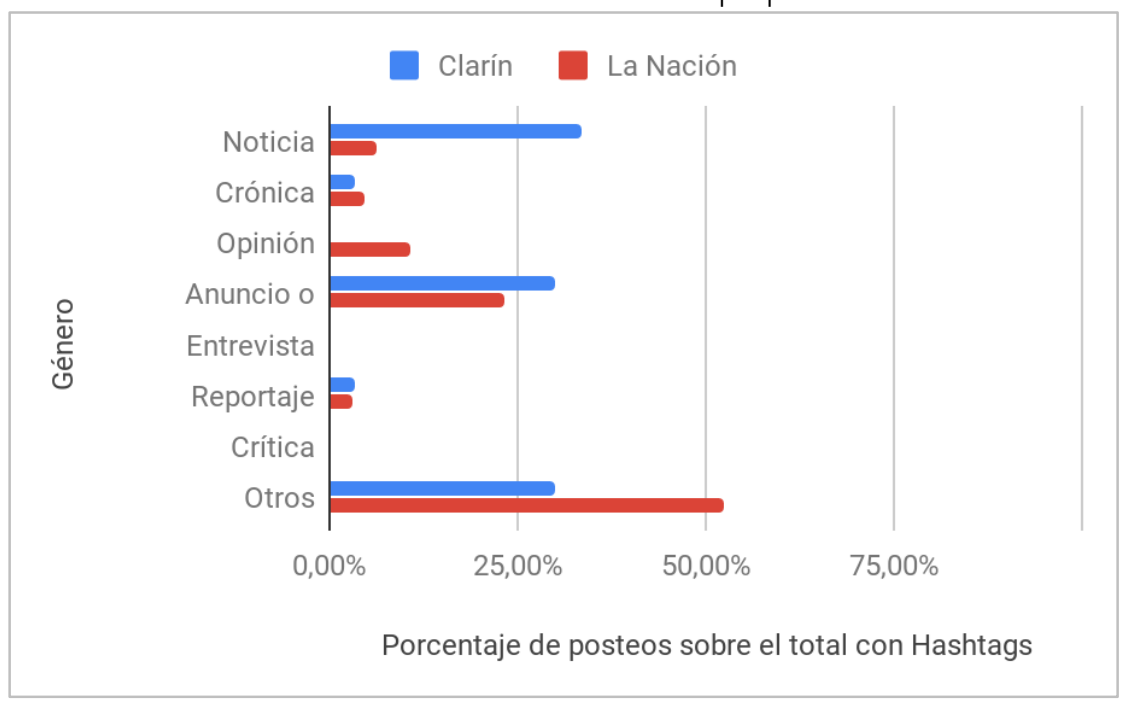

Gráfico 6. Distribución de posteos con hashtags según género periodístico en corpus de base

Respecto a las temáticas de referencia se advierte que prácticamente la mitad de los posteos con hashtag en ambas cuentas corresponden a la categoría Política más precisamente, el 56,67\% ( $n=17)$ en @clarincom y el 46,15\% ( $n=30)$ en @lanacion. La mitad restante presenta distintos comportamientos en cada diario. Clarín la distribuye sólo en dos temáticas: $36,67 \%(n=11)$ en Deportes y 6,67\% (2) en Propio medio y su público; mientras que La Nación la reparte en otras 7 temáticas entre las que se destacan Otro $(12,31 \% ; n=8)$, Deportes $(10,77 \% ; n=7)$ y Sociedad $(10,77 \% ; n=7)$.

Fuente: elaboración propia.

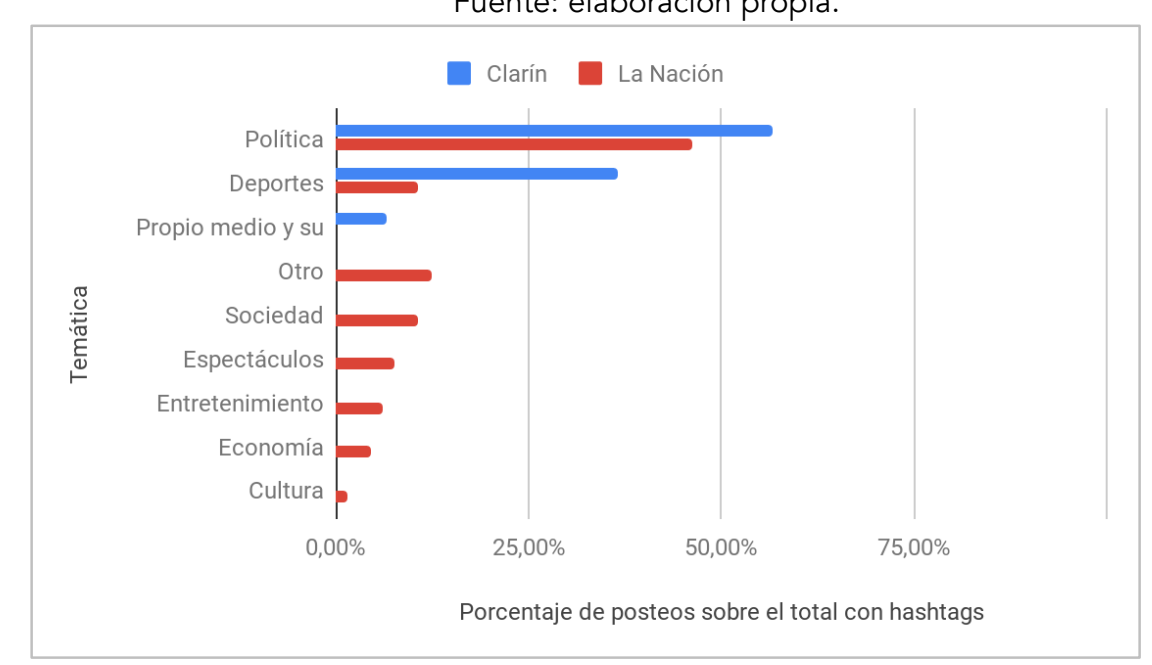

Gráfico 7. Distribución de posteos con hashtags según temática de referencia en corpus de base 
Acerca de los hashtags más utilizados (ver imagen 5), puede observarse que ambas fanpages emplean esta herramienta mayormente para etiquetar series de contenidos mediáticos propios. En @lanacion, los tres hashtags más utilizados son \#Humor, \#ConversacionesLN y \#Efemerides, y entre ellos concentran el 59,94\% $(n=1381)$ del total de etiquetas. En @clarincom, los hashtags \#Noctambulos y \#ClarinVivo agrupan el 29,20\% ( $n=481)$.

Por detrás de este uso, se destaca en La Nación el etiquetado de acontecimientos para su seguimiento. De esta manera, los hashtags \#Elecciones2015, \#ArgentinaDebate, \#NiUnaMenos y \#AtentadoEnParis suman el $13,54 \%(n=312)$ y ocupan los puestos del cuarto al séptimo en la tabla de los más utilizados. En Clarín sucede de igual manera: las etiquetas \#Elecciones2015, \#LollapaloozaOnline y \#LollaAR ocupan los puestos del tercero al quinto.

Fuente: elaboración propia.

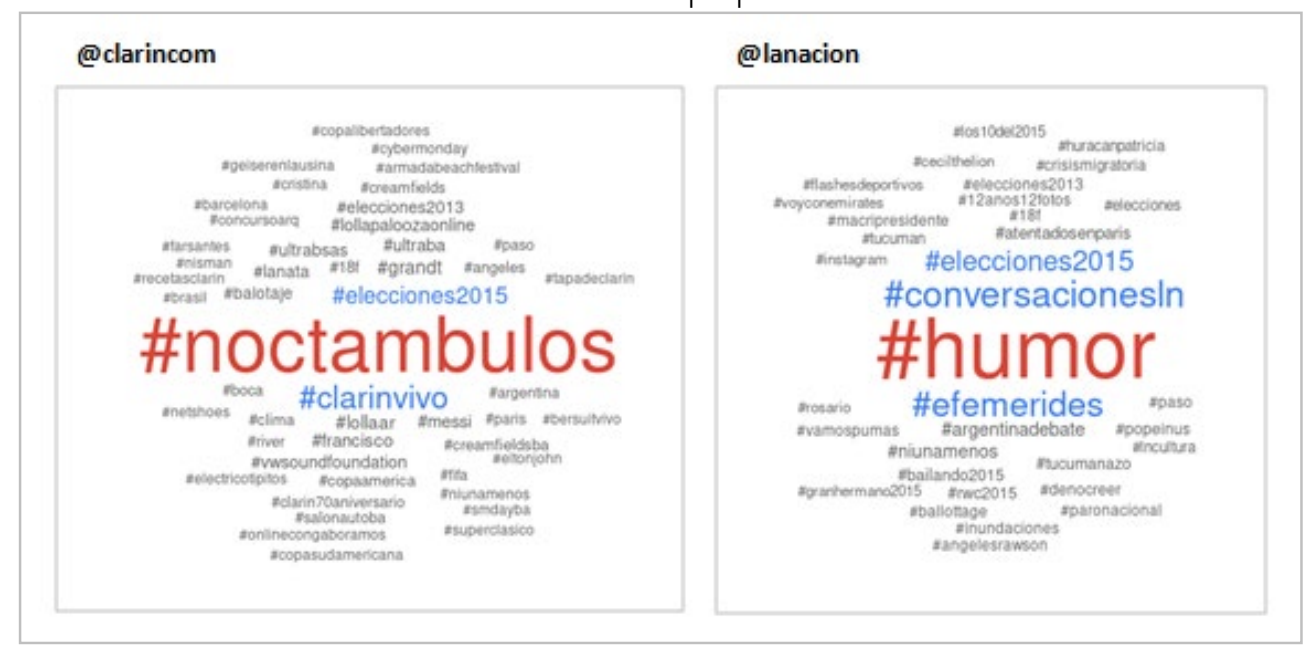

Imagen 5 - Nubes de palabras con hashtags

Para concluir con las apreciaciones acerca de los hashtags, resta decir que los mismos pueden encontrarse en diferentes lugares 0 , incluso, ser el único componente del texto del post (Imagen 6). En estos últimos casos, así como cuando se lo ubica al final, suele empleárselos para etiquetar temas. También se los puede encontrar al comienzo, sobre todo si operan como etiquetas de secciones (por ejemplo, \#8N o \#Noctambulos). Se los ha visto, asimismo, utilizados para proponer consignas o campañas a los usuarios: tal es el caso del sintagma "Hoy Día de la Mujer I Entremujeres presenta El segundo spot en el que nos reímos de nosotras mismas. Te invitamos a usar nuestro hashtag y que completes la frase \#NoTodasLasMujeres haciendo click acá: [http://goo.gl/xpZUY]". 


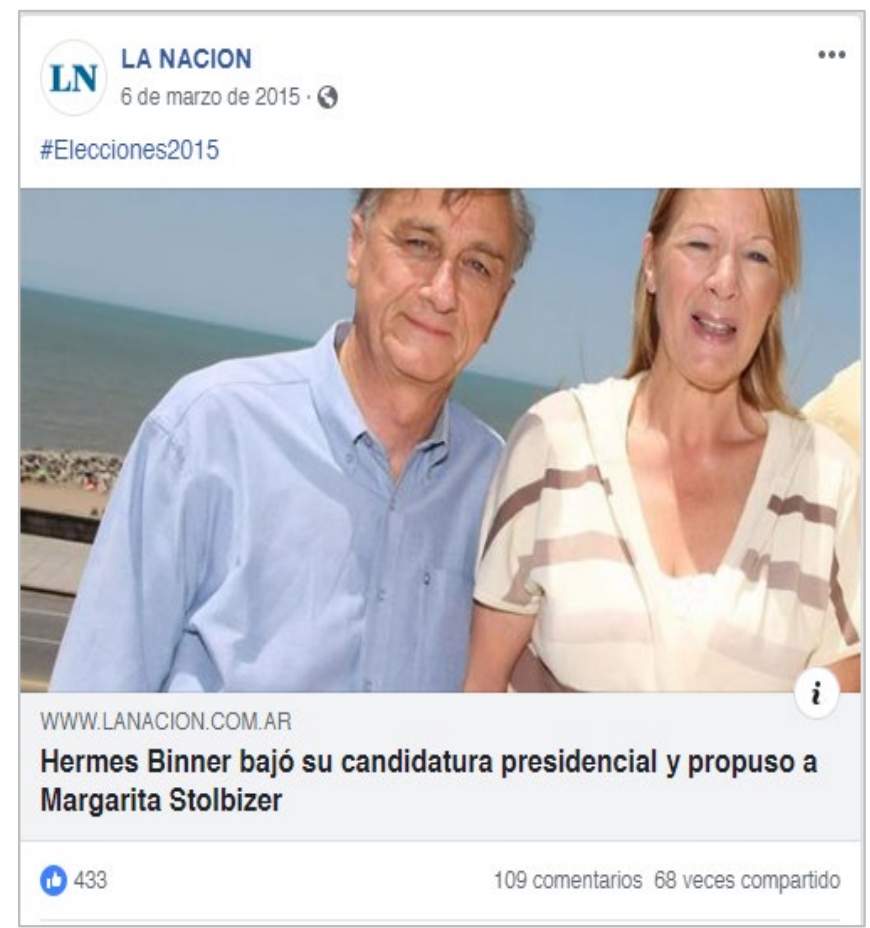

Imagen 6. Posteo de @lanacion con hashtag

Respecto de las menciones, comenzamos por decir que se trata de un elemento que consiste en la generación de un enlace a partir de escribir en una publicación una arroba (@) seguida del nombre de la persona, página o grupo de Facebook al que se quiere remitir. De este modo, la plataforma convierte el nombre citado en un hipervínculo, pero oculta la arroba.

Como puede verse en la tabla 6, en términos de frecuencia de menciones el comportamiento es diferente en ambas cuentas. Mientras que @lanacion las utiliza más que a los corchetes que circunscriben frases y los hashtags, son el recurso paratextual de menor empleo en @clarincom.

Tabla 6. Posteos con al menos una mención

\begin{tabular}{|l|r|r|r|r|r|r|}
\hline & \multicolumn{3}{|c|}{ Clarín } & \multicolumn{3}{c|}{ La Nación } \\
\cline { 2 - 7 } & $\begin{array}{l}\text { Posteos con } \\
\text { Menciones }\end{array}$ & $\begin{array}{r}\text { Posteos } \\
\text { Totales }\end{array}$ & $\begin{array}{c}\text { \% sobre } \\
\text { el total de } \\
\text { posteos }\end{array}$ & $\begin{array}{c}\text { Posteos con } \\
\text { Menciones }\end{array}$ & $\begin{array}{l}\text { Posteos } \\
\text { Totales }\end{array}$ & $\begin{array}{c}\text { \% sobre el } \\
\text { total de } \\
\text { posteos }\end{array}$ \\
\hline $\begin{array}{l}\text { Corpus de } \\
\text { base }\end{array}$ & 24 & 534 & $4,49 \%$ & 126 & 595 & $21,18 \%$ \\
\hline Corpus Total & 1.246 & 29.341 & $4,25 \%$ & 2.955 & 25.401 & $11,63 \%$ \\
\hline
\end{tabular}

Fuente: elaboración propia. 
En cuanto a las menciones más frecuentes (Imagen 7), vale indicar que las cinco cuentas más nombradas en @clarincom son productos propios del multimedio (Clarín Extra Show, Clarín Deportes, Todo Viajes, Entremujeres y Diario Clarín) y acumulan el $35,31 \%$ del total de apariciones de este recurso. En cambio, @lanacion dedica casi un cuarto de sus menciones a personalidades políticas: el usuario Mauricio Macri aparece en el 11,61\% $(n=343)$ del total de posteos que utilizan este recurso; le siguen Daniel Scioli con el 6,77\% $(n=200)$ y Cristina Fernández de Kirchner con el 5,79\% $(n=171)$. Además, también se utilizan con frecuencia referencias a los protagonistas de su sección Humor: las cuentas Batu Tute, Humor Petiso y Gaturro suman juntas el 15,23\% de todos los posteos con menciones.

Fuente: elaboración propia.

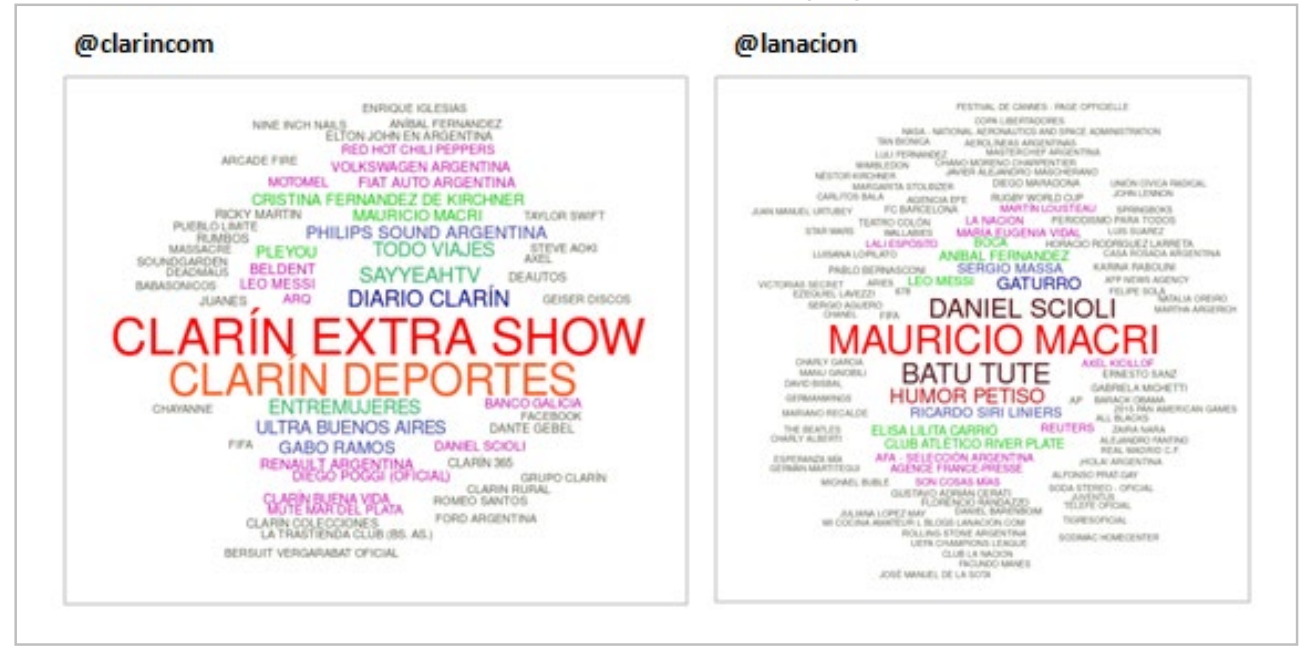

Imagen 7 - Nubes de palabras con menciones

Respecto del lugar que ocupa este elemento al interior del texto de los posteos, puede observarse que cuando se trata de mencionar a productos del propio medio, se ubican, en general, al final de la publicación; mientras que cuando se trata de personas, la mención aparece insertada en el texto.

Finalmente, al analizar las menciones clasificadas según la temática de referencia en el corpus de base (Gráfico 8), se identifica que la fanpage de Clarín tiene cierta predilección por reenviar a cuentas relacionadas con el mundo del entretenimiento, categoría que nuclea el 41,67\%. $(n=10)$ de los posteos con menciones en dicho medio. Mientras que la de La Nación, como se dijo anteriormente, aplica este recurso mayoritariamente en publicaciones referentes a la política, acaparando el $40,48 \%(n=51)$. 
Fuente: elaboración propia.

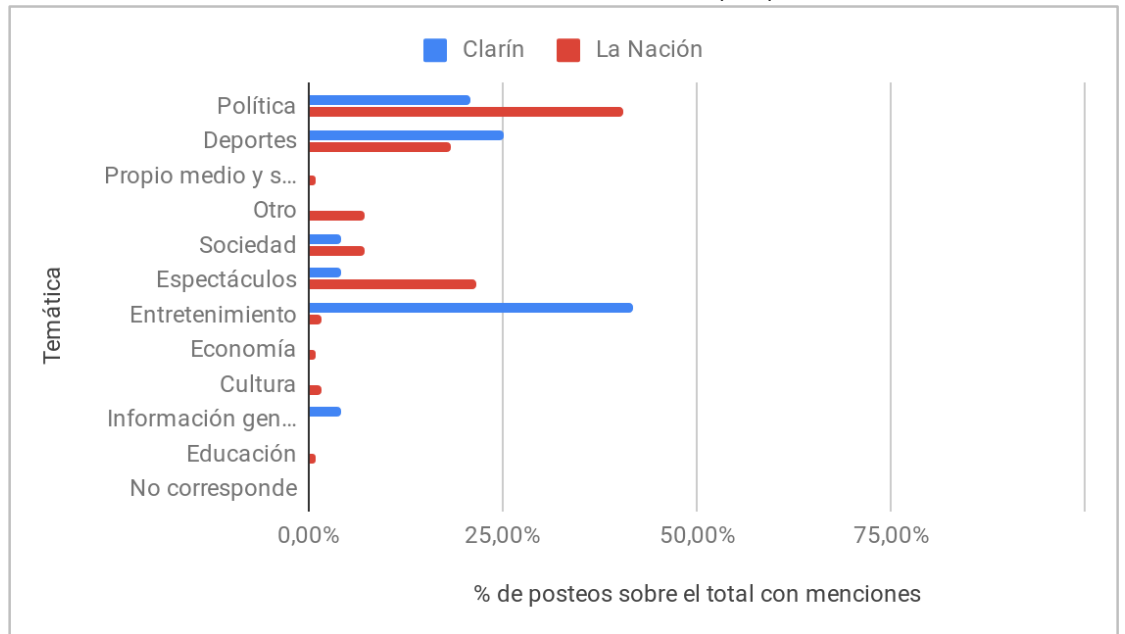

Gráfico 8. Distribución de posteos con menciones según temática de referencia en corpus de base

\section{Los emoticones y su polivalencia paralingüística}

Según Sampietro (2016), tanto los emoticones como los emojis son "representaciones esquemáticas de expresiones faciales o pequeñas imágenes que se añaden a los mensajes electrónicos" (p. 15). La diferencia entre ellos radica en que los primeros son emoticonos textuales porque "se componen de signos de puntuación (...) [que] se leen inclinando la cabeza hacia la izquierda" (p. 15), mientras que los segundos consisten en emoticonos gráficos, "constituidos por pequeñas imágenes prediseñadas" (Sampietro, 2016: 15). Según se tiene registro (Cfr. Dresner y Herring, 2010), es en 1982 cuando Scott Fahlman, informático de la Universidad Carnegie Mellon, propone por primera vez el uso de dos tipos de "caritas" construidas con caracteres como una alternativa para indicar, en mensajes publicados en un foro de discusión sobre informática, que algo ha sido dicho en broma (o no).

Concretamente, sobre los resultados del relevamiento de los posteos de @clarincom y @lanacion se comienza por decir que, en ambas cuentas, la presencia de los emoticones o emojis ${ }^{17}$ es irrelevante en términos de cantidad (Tabla 7). De hecho, en ambos corpus su empleo es realmente exiguo, aunque hay ciertas diferencias en su distribución temporal. En el caso de @lanacion el uso de este recurso paralingüístico comienza en 2012 (en sólo 7 posteos; n=7), y crece en cantidad nominal -aunque no siempre en porcentaje interanual sobre el total

17 En este trabajo se utilizan indistintamente los términos emoticon y emoji. Vale señalar, también, que la extracción de datos de la plataforma se realizó mediante la aplicación Netvizz, y esta herramienta no distingue claramente entre ambos signos de tipo icónico; por ejemplo, en ocasiones puede interpretar un corazón como "<3" o como $\bullet$, así como reemplazarlo por un signo de pregunta en caso de que no le sea posible interpretarlo. 
de los posteos publicados por la cuenta, tal como lo muestra el decaimiento de la línea roja en 2015 (Gráfico 9)- durante $2013(n=25), 2014(n=40)$ y $2015(n=51)$. En cambio, en @clarincom el primer movimiento en este sentido se observa ya en 2011 (cuando se publican 4 posteos con emojis; $n=4$ ), pero en 2012 desaparece y en 2013 es escaso $(n=5)$, creciendo significativamente recién en 2014 cuando se advierte un pico $(n=54)$ que luego vuelve a caer abruptamente en $2015(n=5)$.

Tabla 7. Posteos con emoticones o emojis

\begin{tabular}{|l|r|r|r|r|r|r|}
\hline & \multicolumn{3}{|c|}{ Clarín } & \multicolumn{3}{c|}{ La Nación } \\
\cline { 2 - 7 } & $\begin{array}{c}\text { Posteos } \\
\text { con } \\
\text { Emojis }\end{array}$ & $\begin{array}{c}\text { Posteos } \\
\text { Totales }\end{array}$ & $\begin{array}{c}\text { cl sobre } \\
\text { de } \\
\text { posteos }\end{array}$ & $\begin{array}{c}\text { Posteos } \\
\text { con Emojis }\end{array}$ & $\begin{array}{c}\text { Posteos } \\
\text { Totales }\end{array}$ & $\begin{array}{c}\text { \% sobre el } \\
\text { total de } \\
\text { posteos }\end{array}$ \\
\hline Corpus de base & 2 & 534 & $0,37 \%$ & 6 & 595 & $1,01 \%$ \\
\hline Corpus Total & 68 & 29.341 & $0,23 \%$ & 123 & 25.401 & $0,48 \%$ \\
\hline
\end{tabular}

Fuente: elaboración propia.

Fuente: elaboración propia.

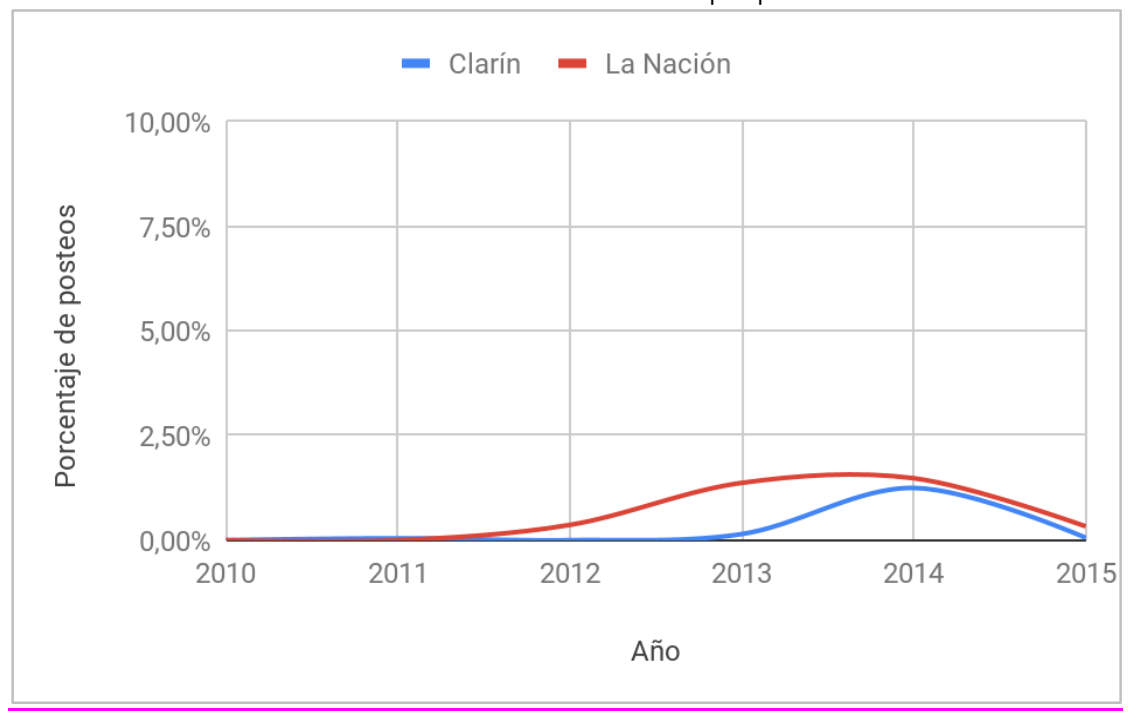

Gráfico 9. Distribución de posteos con emojis en el tiempo

Sobre el empleo de este atributo paralingüístico respecto del momento del día en que las cuentas realizan las publicaciones, y tal como sucedía con los corchetes, se nota que @clarincom emplea emoticones, preferencialmente, en los posteos nocturnos, mientras @lanacion lo hace con mayor asiduidad por la tarde y, en segundo lugar, por la mañana (Tabla 8). 
Tabla 8. Distribución de posteos con emoticones según franja horaria en corpus total

\begin{tabular}{|l|r|r|r|r|r|r|}
\hline & \multicolumn{4}{|c|}{ Clarín } & \multicolumn{3}{c|}{ La Nación } \\
\cline { 2 - 7 } & $\begin{array}{c}\text { Cant. de } \\
\text { posteos con } \\
\text { emoticon }\end{array}$ & $\begin{array}{c}\text { Cant. por } \\
\text { turno }\end{array}$ & $\begin{array}{c}\text { \% sobre el } \\
\text { total de } \\
\text { posteos por } \\
\text { turno }\end{array}$ & $\begin{array}{c}\text { Cant. de } \\
\text { posteos con } \\
\text { emoticon }\end{array}$ & $\begin{array}{c}\text { \%olo el } \\
\text { Cant. por } \\
\text { turno }\end{array}$ & $\begin{array}{c}\text { posteos por } \\
\text { turno }\end{array}$ \\
\hline Mañana & 6 & 9004 & $0,07 \%$ & 36 & 8757 & $0,41 \%$ \\
\hline Tarde & 23 & 10614 & $0,22 \%$ & 57 & 9886 & $0,58 \%$ \\
\hline Noche & 37 & 7112 & $0,52 \%$ & 29 & 5575 & $0,52 \%$ \\
\hline Madrugada & 2 & 2611 & $0,08 \%$ & 1 & 1183 & $0,08 \%$ \\
\hline Total & 68 & 29341 & & 123 & 25401 & \\
\hline
\end{tabular}

Fuente: elaboración propia.

Por otra parte, no hay nada que agregar en relación con las variables género periodístico, temática o temporalidad de los acontecimientos, dado que la cantidad de posteos que presentan emoticones dentro de los comprendidos en el corpus de base es demasiado escasa como para hacer un análisis en ese sentido. No obstante, retomemos algunas discusiones respecto de las funciones que los emoticonos suelen asumir en la escritura contemporánea, en función de efectuar algunas inferencias sobre las estrategias de empleo encontradas en las cuentas bajo estudio.

En Tascón (2012: 35) se propone que estos se orientan a "transmitir sentimientos cuando acompañan a los mensajes y que contribuyen a una mayor carga oral de los textos"; y agrega: "Los emoticonos han sido solo el principio de la utilización de toda una serie de elementos que intentan paliar las dificultades del texto para transmitir sentimientos y emociones, sobre todo en los mensajes más breves" (Tascón, 2012: 36). Sin embargo, es posible advertir que los emoticones y emojis, además de plasmar caras de alegría, enojo, sorpresa, etc., también permiten manifestar otros aspectos de la entonación expresiva propia del enunciado — tales como el tono de burla, la sorna, la ironía o cualquier posición de adhesión o distancia respecto de otros discursos- que no es fácil reconocer, al interior del texto del post, a través de determinaciones eminentemente lingüísticas como las elecciones de recursos léxicos, gramaticales o composicionales, etc. Incluso, autores como Dresner y Herring (2010: 250) afirman que la función principal de muchos emoticones no es transmitir emociones sino, más bien, un significado de tipo pragmático: "in many typical cases, emoticons indicate the illocutionary force of the text to which they are attached, contributing to its pragmatic meaning, and are thus part and parcel of the linguistic communication channel". En otras palabras, sostienen que: "in many cases emoticons are used not as signs of 
emotion, but rather as indications of the illocutionary force of the textual utterances that they accompany" (p. 255).

Evitando la inmersión en el farragoso terreno de las intencionalidades - ver Raimondo (2010)_, y entendiendo que este estudio no repara en las determinaciones lingüísticas sino en aquellas derivadas de la puesta en discurso, es posible distinguir, sin pretender exhaustividad, los siguientes modos de empleo:

- Modo I: Acompañar visualmente, o reemplazar por una imagen, contenido del texto del post pero sin una función emotiva clara (Imagen 8);

- Modo II: Expresar emociones -y también manifestar valoraciones, es decir, cierta dimensión axiológica- asociadas a una nota compartida mediante el posteo en cuestión (Imagen 9). Muchos de los emojis utilizados por @lanacion se encuentran en posteos de noticias ligadas a la temática "Sociedad", que, como se señaló en Raimondo, Sambrana y Cardoso (2017: 54), podrían calificarse como historias de interés humano (Hughes, 1981) y tienden a la "conformación de una especie de comunidad de sentimientos o comunidad de emociones";

- Modo III: Expresar emociones directamente orientadas al destinatario (Imagen 10) en publicaciones del género Anuncio o posteo de saludo a usuarios y en función de la consolidación de eso que Biselli y Valdettaro (2004) han denominado estrategias discursivas del contacto;

- Modo IV: Vehiculizar aspectos de la entonación expresiva del enunciado (Imagen 11).

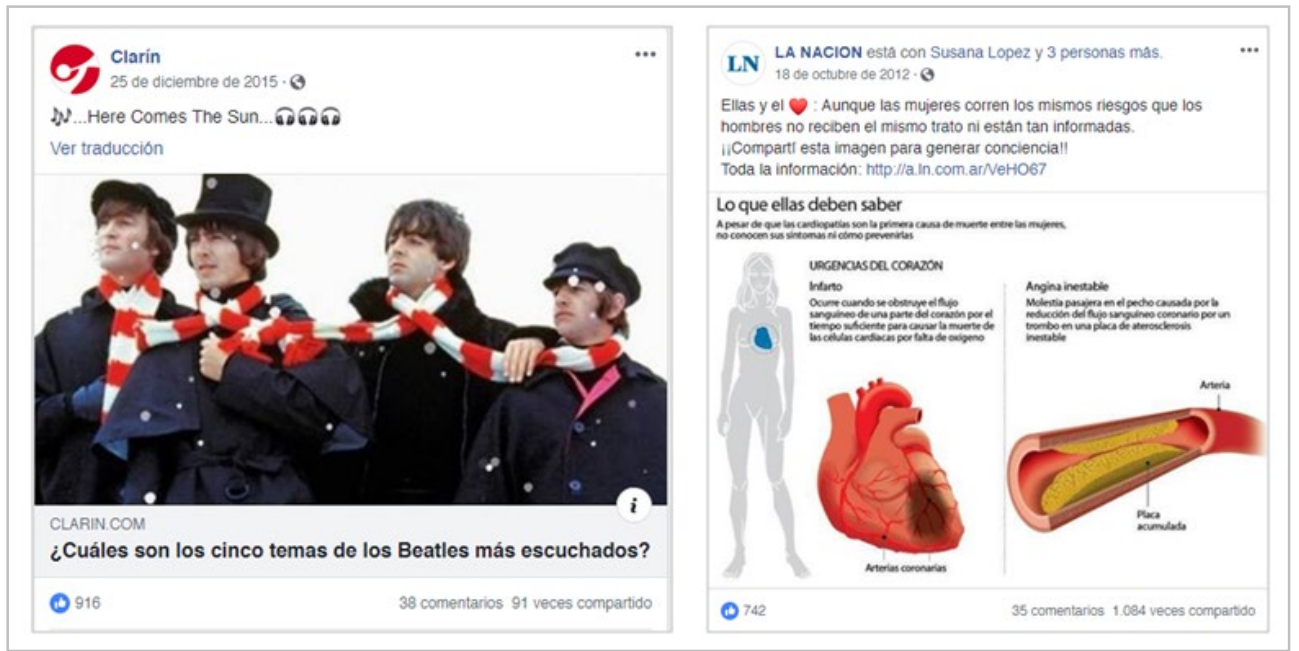

Imagen 8. Posteos con emojis Modo / 


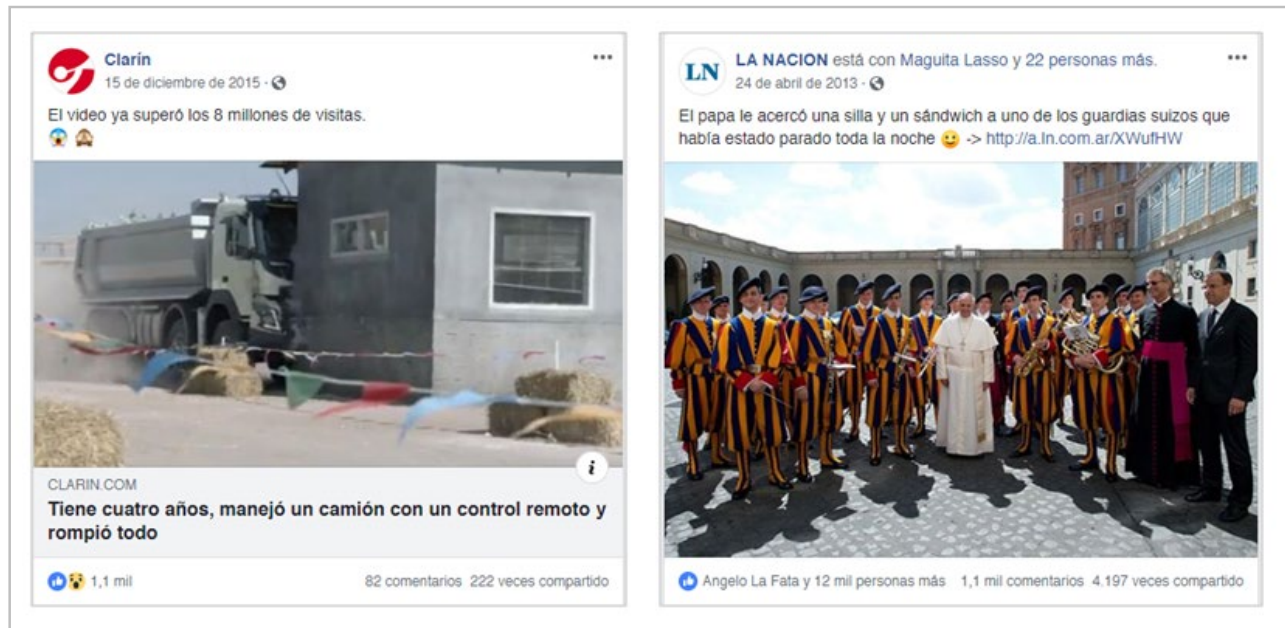

Imagen 9. Posteos de con emojis Modo //

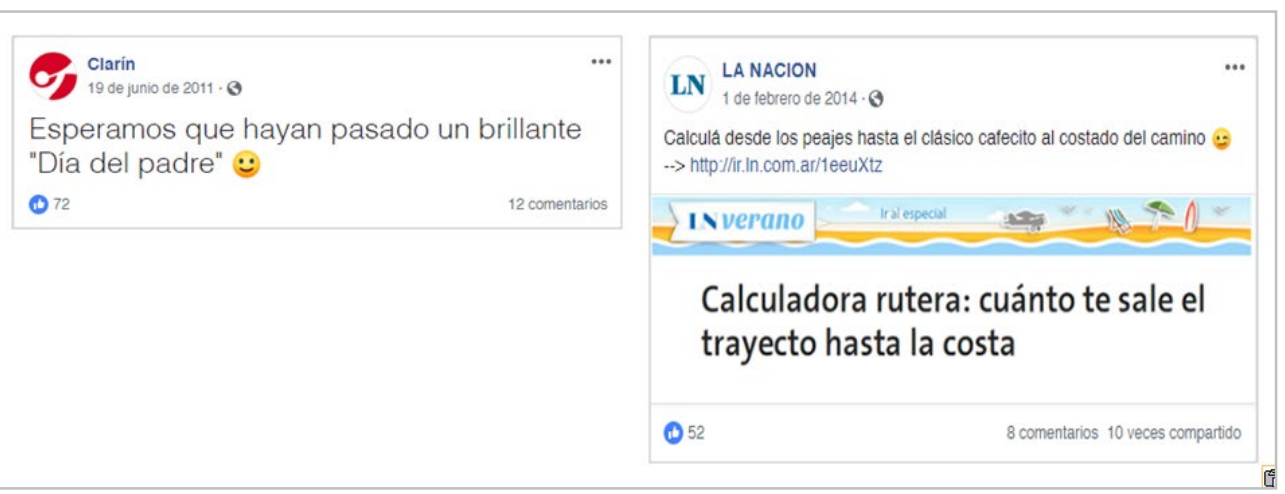

Imagen 10. Posteos de con emoji Modo III

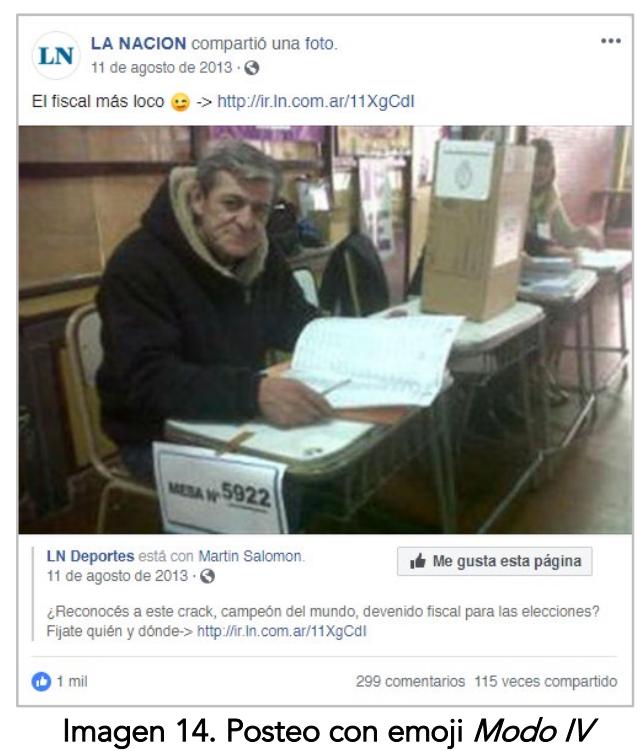


Sintetizando, tal como sucede con el empleo de los corchetes que circunscriben frases, se observa que los emoticones vehiculizan rasgos expresivos o conativos del discurso de información que -en el caso de aquellos posteos que comparten enlaces a noticias- no estaban en las notas que los diarios publican por fuera de la plataforma de Facebook.

\section{Consideraciones finales}

Según Comscore (2018), Facebook está segundo en el market ranking de las 15 propiedades multiplataforma más visitadas por los argentinos; los accesos a esta plataforma están sólo detrás de Google Sites pero antes que los del Grupo Clarín o el Grupo La Nación —que se encuentran en el $3^{\circ}$ y $8^{\circ}$ lugar, respectivamente. Tampoco asombra que los informes de los observatorios de consumo de medios a nivel internacional —Cfr. Shearer y Matsa (2018) — indiquen que la tendencia es que el acceso a la información se dé, cada vez más, con algún tipo de mediación de las llamadas redes sociales en Internet y, muy frecuentemente, in between time $^{18}$ (Igarza, 2009) y mediante un artefacto con pantalla en particular, el smartphone. Todo esto más allá de las constantes fluctuaciones que atraviesan las distintas plataformas de "redes" y el decaimiento en los niveles de confianza que tienen los públicos tanto respecto de estas como de los medios tradicionales. Tal como puede leerse en el más reciente informe de Reuters (2018: 113), en Argentina:

Social media are a popular source of news, used by $72 \%$, including $60 \%$ who get information on Facebook, 37\% on WhatsApp, and 27\% on YouTube. Seven out of ten mention the smartphone as a device to access information, compared to $63 \%$ that access news on their computers, and $17 \%$ that use a tablet).

Por otra parte, es difícil no compartir la idea de que estas plataformas operan como infraestructuras performativas, tal como propone Gillespie (2010) o Van Dijck (2016), en tanto están investidas de determinadas figuraciones y moldean la performance de los actores sociales así como los contenidos mediáticos que por ellas circulan. Algo que, de hecho, se ha podido comprobar a lo largo de todo este artículo.

Comprender cómo cambia el discurso de la prensa en general -y el discurso de información en particular- al ser puesto en circulación a través de Facebook permite reconocer y desnaturalizar sus propiedades, advirtiendo su condición histórica y el modo en que su fisonomía va modificándose de acuerdo a los soportes y ambientes en los que se inscribe. Al mismo tiempo, hace posible escudriñar cómo estos medios van adaptando el contrato -en tanto noción que "pone el acento en las condiciones de construcción del vínculo que en el tiempo

18 Autores como Mancini (2011) e Igarza (2009) hace tiempo han problematizado el tiempo de atención de la audiencia, considerando que este se encuentra cada vez más atomizado y que el público consume "en píldoras, en todo momento y en cualquier parte" (Mancini, 2011: 24). 
une a un medio con sus consumidores" (Verón, 2004: 223)— que le proponen a sus públicos lectores para sobrevivir en la turbulenta actualidad. De este modo, puede decirse que las fanpages de los periódicos estudiados no son meras vías rápidas para controlar el tráfico hacia el propio sitio web. Son, muchas veces, el único entorno o dominio en donde gran parte de los usuarios se encuentran con las noticias y, tal vez, una extraordinaria oportunidad para construir lazos de tipos más bien comunitarios ${ }^{19}$ entre y con los usuarios —más allá de si estos se consideran o no lectores de un determinado diario y si se sienten afines a su línea editorial. La pretensión de poder oficiar como nexo comunitario es, incluso, algo que está presente en la lógica de los medios tradicionales mucho antes de su pasaje por las "redes". Esto es lo que se observó, por ejemplo, en Raimondo (2012: 306), a la hora de estudiar los espacios de intervención y participación del lector que Clarín y La Nación disponen en sus respectivas interfaces online, "con el objetivo de que la audiencia se identifique con ellos -más allá del perfil editorial-, intentando crear experiencias que excedan el consumo de noticias e información".

Lo expresado en este escrito nos permite seguir avanzando en el objetivo de conocer cómo enuncian los diarios en las redes, proveyendo una descripción pormenorizada del modo en que las fanpages de Clarín y La Nación han empleado esos elementos del texto del post que hemos reconocido aquí como paratextuales y paralingüísticos, a lo largo del período 2010-2015. Los corchetes, los hashtags, las menciones y los emoticones o emojis han adquirido propiedades peculiares en la comunicación digital online, y su empleo en el marco del discurso periodístico es ciertamente novedoso. En otras palabras, más allá de sus diferencias, los recursos paratextuales y paralingüísticos analizados son parte de los atributos específicos que presenta el discurso de la prensa en Facebook y, probablemente - aunque no lo hemos comprobado en este estudio, en tanto es ajeno a nuestro objeto-, también en otras plataformas conectivas como Twitter o Instagram.

\footnotetext{
19 Sin ánimos de tomar livianamente una noción tan trabajada desde el pensamiento sociológico pero, por otro lado, sin tiempo ni espacio suficiente para realizar un desarrollo más exhaustivo, nos contentamos con indicar que el término comunidad remite aquí a esa forma de socialización asentada en "lazos prerracionales, como aquellos que nacen a partir del afecto, de los usos y de las interdependencias" (Honneth, 1999: 8).
} 


\section{Referencias bibliográficas}

BAJTíN, M. (1998): El problema de los géneros discursivos. En Estética de la creación verbal, pp. 248-294. Buenos Aires, Siglo XXI.

BISELLI, R. y VALDETTARO, S. (2004): Las estrategias discursivas del contacto en la prensa escrita. La Trama de la Comunicación, Vol. 9.

BURBULES, N. (1998): Rhetorics of the Web: Hyperreading and critical literacy. En SNYDER, I. (Ed.), Page to screen: taking literacy into the electronic era (102-122) Londres, Routledge.

CASSANY, D. (2003): Escritura electrónica. Revista C\&E, Vol. 13, N.3. https://repositori.upf.edu/bitstream/handle/10230/27137/cassany_cye_escr.pdf [Consultado: 19-02-2019].

CLARÍN (1997): Manual de estilo. Buenos Aires, Aguilar.

COMSCORE (2018): Rankings Digitales de Argentina para Diciembre 2018. https://www.comscore.com/lat/Insights/Rankings?utm_campaign=LATAM_AR_FE B2019_MR_MMX_MPDEC2018\&utm_medium =email\&utm_source $=$ comscore_elq _LATAM_AR_FEB2019_MR_MMX_MPDEC2018\&cs_edgescape_cc=AR\&elqTrackl $\mathrm{d}=852 \mathrm{~b} 217 \mathrm{e} 0 \mathrm{a} 6348 \mathrm{bfb} 616114 \mathrm{f31} \mathrm{c} 2 \mathrm{f} 608 \& \mathrm{elq}=\mathrm{b} 7 \mathrm{f} 8074 \mathrm{fdf0} \mathrm{c} 4 \mathrm{~b} 3 \mathrm{fa} 7901594 \mathrm{ce} 14 \mathrm{f} 7$ 07\&elqaid=8366\&elqat $=1$ \&elqCampaignld $=5060$ [Consultado: 15-02-2019].

DRESNER, E. y HERRING, S. (2010): Functions of the Nonverbal in CMC: Emoticons and Illocutionary Force. Communication Theory, 20, pp. 249-268.

EL-ARINI, K. (2014): Click-baiting. En Facebook. Newssroom, 25 de agosto. https://newsroom.fb.com/news/2014/08/news-feed-fyi-click-baiting [Consultado: 26-07- 2018].

FISHER, S. y VERÓN, E. (1986): Théorie de l'énonciation et discourssociaux. Etudes de lettres, 211, 71-92. (Teoría de la enunciación y discursos sociales. Traducción al español de Mollinedo, S. para la cátedra Teorías y Medios de Comunicación, UBA):

GENETTE, G. (1989): Palimpsestos. La literatura en segundo grado. Madrid, Taurus.

GILLESPIE, T. (2010): The politics of platforms. New Media \& Society, 12(3), 347364.

GONZÁLEZ-FERNÁNDEZ-VILLAVICENCIO, N. (2014): El \#hashtag ya tiene historia. Anuario ThinkEPI, Vol. 8 (326-330): 
HONNETH, A. (1999): Comunidad. Esbozo de una historia conceptual. Isegoría, Revista de Filosofía Moral y Política, $N^{\circ} 20$. http://isegoria.revistas.csic.es/index.php/isegoria/article/view/89/89 [Consultado: 28-08-2011):

HUGHES, H. (1981): News and the human interest story. New Brunswick. Transaction.

IGARZA, R. (2009): Burbujas de ocio: nuevas formas de consumo cultural. Buenos Aires, La Crujía.

JAKOBSON, R. (1975): Lingüística y Poética. En Ensayos de lingüística general. Barcelona, Seix Barral.

LEVENBERG, R. (2017): Caminos de letras: los periodistas en la transición desde la máquina de escribir al trabajo digital. El caso de La Nación (1995-2013): Tesis para optar por el título de Doctor en Ciencias Sociales, Universidad de Buenos Aires.

MANCINI, P. (2011): Hackear el periodismo. Manual de laboratorio. Buenos Aires, La Crujía.

MENNA, L. (2012): Nuevas formas de significación en red: el uso de las etiquetas en el movimiento 15M. Revista Estudios de lingüística del español. Vol. 34, Núm. 1 (1-61): https://www.raco.cat/index.php/Elies/article/view/271561 [Consultado: 13-02-2019].

RAIMONDO, N. (2010): El ocaso del modelo intencional: cómo pensar la noción de 'estrategia discursiva' desde una mirada sociosemiótica. Revista Latinoamericana de Comunicación Chasqui, N. 111, pp. 14-18.

(2012): La prensa online y su público. Un estudio de los espacios de intervención y participación del lector en Clarín y La Nación. Buenos Aires, Teseo.

RAIMONDO, N., CARDOSO, A. y ROSTAGNO, J. (2018): Articulación artesanalcomputacional para el estudio interdisciplinario de posteos en cuentas de Facebook. Relato de una experiencia asequible. Simposio Argentino sobre Tecnología y Sociedad, $47 \mathrm{JIIO}$ (Jornadas Argentinas de Informática), Universidad Nacional de Palermo, Ciudad Autónoma de Buenos Aires, 3 al 7 de septiembre.

RAIMONDO, N., CARDOSO, A., ROSTAGNO, J. y SAMBRANA, A. (2018): El discurso de la prensa argentina en tiempos de algoritmos: una mirada diacrónica sobre la composición de posteos en las fanpages de Clarín y La Nación. Âncora, Revista Latino-americana de Jornalismo, Vol. 5(1), DOI: 10.22478/ancora.v5n1p3159. 
RAIMONDO, N., SAMBRANA, A. y CARDOSO, A. (2017): Medios tradicionales y redes sociales en Internet: un análisis de los posteos compartidos por los diarios argentinos Clarín y La Nación en Facebook (2010-2015): Revista Astrolabio Nueva Época, número 19.

REUTERS (2018): Digital News Report 2018. Disponible en: http://www.digitalnewsreport.org/survey/2018/argentina-2018/ [Consultado: 1502-2019].

SAMPIETRO, A. (2016): Emoticonos y emojis. Análisis de su historia, difusión y uso en la comunicación digital actual. Tesis para acceder al Doctorado en Lenguajes y Literaturas de la Universitat de València. http://infoling.org/repository/PhDdissInfoling-83-5-2016.pdf [Consultado: 25-07-2018].

SHEARER, E. y MATSA, K. (2018): News Use Across Social Media Platforms 2018. Pew Research Center. http://www.journalism.org/2018/09/10/news-use-acrosssocial-media-platforms-2018/ [Consultado: 15-02-2019].

STERN, M. (2006): Puntuación. En García Negroni, María Marta, Pérgola, Laura y Stern, Mirta El arte de escribir bien en español. Manual de corrección de estilo. Nueva edición actualizada 2006. Buenos Aires, Santiago Arcos.

TASCÓN, M. (2012): Escribir en Internet. Guía para los nuevos medios y las redes sociales. Barcelona, Galaxia Gutemberg.

VAN DIJCK, J. (2016): La cultura de la conectividad. Una historia crítica de las redes sociales. Buenos Aires, Siglo XXI.

VÁZQUEZ-CANO, E., FOMBONA, J. y BERNA, C. (2016): Análisis computacional de las características ortotipográficas y paralingüísticas de los tweets periodísticos. El profesional de la información, V. 25, n. 4, pp. 588-598.

VERÓN, E. (1983): Construir el acontecimiento. Los medios de comunicación masiva y el accidente de ThreeMile Island. Buenos Aires, Gedisa.

(1985): El análisis del Contrato de Lectura. Un nuevo método para los estudios de posicionamiento de los soportes de los media [Traducción al español de L'analyse du 'contrat de lecture': une nouvelleméthodepour les études de positionnement des supportspresse]. En Touati, E. Les Medias: Experiences, recherchesactuelles, aplications. París, IREP.

(1998): La semiosis social. Fragmentos de una teoría de la discursividad. Buenos Aires, Gedisa. 
- Natalia Raimondo Anselmino, Ana Laura Cardoso, José Rostagno, Alejandro Matías Sambrana

VERÓN, E. (2004): Fragmentos de un tejido. Buenos Aires, Gedisa. 